\title{
7.1A $\mathrm{A}^{\text {Average }}$ ratas agansts sterting(3.1.1)
}

\begin{tabular}{|c|c|c|c|c|c|c|c|c|c|c|c|c|}
\hline & & Broad & & & & & Exchar & ge rates & & & & \\
\hline & $\begin{array}{r}\text { exchange } \\
\text { rate index } \\
\text { January } \\
2007=100^{1}\end{array}$ & $\begin{array}{r}\text { exchange } \\
\text { rate index } \\
\text { January } \\
2007=100^{2}\end{array}$ & Euro $^{3}$ & $\begin{array}{r}\text { Australian } \\
\text { dollar }\end{array}$ & $\begin{array}{r}\text { Canadian } \\
\text { dollar }\end{array}$ & $\begin{array}{r}\text { Czech } \\
\text { Koruna }\end{array}$ & $\begin{array}{c}\text { Cypriot } \\
\text { Pound }\end{array}$ & $\begin{array}{l}\text { Danish } \\
\text { kroner }\end{array}$ & $\begin{array}{c}\text { Estonian } \\
\text { Kroon }\end{array}$ & $\begin{array}{l}\text { Hong } \\
\text { Kong } \\
\text { dollar }\end{array}$ & $\begin{array}{r}\text { Hungarian } \\
\text { Forint }\end{array}$ & $\begin{array}{r}\text { Monthly } \\
\text { average } \\
\text { Indian } \\
\text { rupee }\end{array}$ \\
\hline & BK67 & BK82 & THAP & AJFP & AJFB & BK25 & BK22 & AJFK & BK28 & AJFU & BK33 & BK97 \\
\hline 2005 & 100.3883 & 100.3167 & 1.4629 & 2.3851 & 2.2048 & 43.5537 & 0.8437 & 10.9013 & 22.8867 & 14.1477 & 362.8009 & \\
\hline 2006 & 101.1883 & 100.9817 & 1.4670 & 2.4460 & 2.0900 & 41.5666 & 0.8446 & 10.9427 & 22.9524 & 14.3182 & 387.5955 & \\
\hline 2007 & 103.5792 & 103.1775 & 1.4619 & 2.3899 & 2.1467 & 40.6006 & 0.8517 & 10.8921 & 22.8759 & 15.6201 & 367.3316 & \\
\hline 2008 & 90.7792 & 90.4392 & 1.2588 & 2.1881 & 1.9621 & 31.3855 & 0.7367 & 9.3853 & 19.7029 & 14.4304 & 316.5264 & \\
\hline 2009 & 80.1404 & 80.1263 & 1.1233 & 1.9905 & 1.7800 & 29.7000 & 0.6580 & 8.3644 & 17.5760 & 12.1432 & 314.8780 & .. \\
\hline 2006 Jan & 99.0600 & 98.8700 & 1.4582 & 2.3566 & 2.0469 & 41.8419 & 0.8365 & 10.8799 & 22.8155 & 13.7079 & 365.5479 & \\
\hline Feb & 98.9300 & 98.7200 & 1.4637 & 2.3562 & 2.0079 & 41.5988 & 0.8406 & 10.9256 & 22.9015 & 13.5566 & 368.3035 & \\
\hline Mar & 98.3600 & 98.1900 & 1.4500 & 2.4009 & 2.0184 & 41.5328 & 0.8340 & 10.8189 & 22.6880 & 13.5288 & 378.3270 & \\
\hline Apr & 98.3600 & 98.1800 & 1.4402 & 2.3995 & 2.0232 & 41.0494 & 0.8300 & 10.7464 & 22.5340 & 13.7172 & 382.0883 & \\
\hline May & 101.2100 & 101.0000 & 1.4637 & 2.4479 & 2.0764 & 41.3623 & 0.8416 & 10.9144 & 22.9024 & 14.5016 & 383.9396 & \\
\hline Jul & 100.8600 & 100.7100 & 1.4540 & 2.4513 & 2.0819 & 41.3643 & 0.8359 & 10.8477 & 22.7505 & 14.3403 & 403.0065 & \\
\hline Aug & 102.8600 & 102.6800 & 1.4785 & 2.4818 & 2.1200 & 41.6899 & 0.8513 & 11.0312 & 23.1336 & 14.7318 & 405.4426 & \\
\hline Sep & 102.9200 & 102.7400 & 1.4811 & 2.4951 & 2.1037 & 42.0352 & 0.8537 & 11.0495 & 23.1745 & 14.6679 & 406.3963 & \\
\hline Oct & 103.0600 & 102.8200 & 1.4869 & 2.4886 & 2.1164 & 42.0482 & 0.8573 & 11.0857 & 23.2652 & 14.6027 & 396.6763 & \\
\hline Nov & 103.3700 & 103.0800 & 1.4834 & 2.4750 & 2.1731 & 41.5653 & 0.8569 & 11.0610 & 23.2107 & 14.8788 & 383.9409 & .. \\
\hline Dec & 104.4000 & 104.0600 & 1.4860 & 2.4981 & 2.2636 & 41.2701 & 0.8589 & 11.0778 & 23.2503 & 15.2611 & 377.2499 & 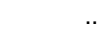 \\
\hline 2007 Jan & 105.4500 & 105.1200 & 1.5079 & 2.5022 & 2.3038 & 41.9983 & 0.8721 & 11.2397 & 23.5936 & 15.2780 & 382.8367 & \\
\hline Feb & 104.9100 & 104.5700 & 1.4969 & 2.5017 & 2.2931 & 42.2740 & 0.8670 & 11.1580 & 23.4213 & 15.2958 & 379.2024 & \\
\hline Mar & 103.4400 & 103.0700 & 1.4703 & 2.4555 & 2.2746 & 41.2448 & 0.8525 & 10.9532 & 23.0055 & 15.2139 & 366.8674 & \\
\hline Apr & 104.1300 & 103.7100 & 1.4713 & 2.4034 & 2.2553 & 41.2100 & 0.8554 & 10.9661 & 23.0211 & 15.5602 & 361.7697 & \\
\hline May & 103.7700 & 103.3600 & 1.4677 & 2.4034 & 2.1717 & 41.4427 & 0.8557 & 10.9369 & 22.9639 & 15.5105 & 364.8435 & \\
\hline Jun & 104.3800 & 104.0000 & 1.4805 & 2.3580 & 2.1156 & 42.2782 & 0.8640 & 11.0222 & 23.1650 & 15.5216 & 370.1210 & 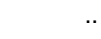 \\
\hline Jul & 105.0900 & 104.6700 & 1.4821 & 2.3451 & 2.1365 & 42. & 0.8658 & 11.0284 & 901 & 039 & & \\
\hline Aug & 104.4100 & 104.0500 & 1.4762 & 2.4286 & 2.1284 & 41.1191 & 0.8625 & 10.9872 & 23.0970 & 15.7186 & 376.7223 & \\
\hline Sep & 103.1700 & 102.8000 & 1.4515 & 2.3859 & 2.0723 & 40.0153 & 0.8481 & 10.8150 & 22.7115 & 15.7091 & 367.7689 & \\
\hline Oct & 102.6700 & 102.2300 & 1.4370 & 2.2746 & 1.9953 & 39.2714 & 0.8396 & 10.7107 & 22.4839 & 15.8555 & 360.5674 & \\
\hline 2008 Jan & 96.4800 & 95.9900 & 1.3383 & 2.2347 & 1.9929 & 34.8639 & 0.7833 & 9.9708 & 20.9404 & 15.3738 & 342.6374 & \\
\hline Feb & 95.9900 & 95.4800 & 1.3316 & 2.1512 & 1.9625 & 33.7860 & 0.7794 & 9.9259 & 20.8355 & 15.3121 & 349.1247 & \\
\hline Mar & 94.5300 & 94.1100 & 1.2897 & 2.1672 & 2.0047 & 32.4593 & 0.7549 & 9.6163 & 20.1793 & 15.5885 & 335.3933 & \\
\hline Apr & 92.7400 & 92.3300 & 1.2580 & 2.1300 & 2.0113 & 31.5177 & 0.7363 & 9.3855 & 19.6832 & 15.4403 & 318.7565 & \\
\hline May & 92.6900 & 92.3100 & 1.2633 & 2.0697 & 1.9626 & 31.7115 & 0.7394 & 9.4255 & 19.7661 & 15.3190 & 312.8188 & \\
\hline Jun & 92.8100 & 92.3900 & 1.2636 & 2.0669 & 1.9976 & 30.7086 & 0.7396 & 9.4244 & 19.7702 & 15.3478 & 306.5536 & . \\
\hline Jul & 92.9400 & 92.4800 & 1.2615 & 2.0662 & 2.0141 & 29.7090 & 0.7384 & 9.4109 & 19.7382 & 15.5067 & 144 & \\
\hline Aug & 91.3600 & 90.9600 & 1.2614 & 2.1400 & 1.9905 & 30.6396 & 0.7383 & 9.4095 & 19.7369 & 14.7490 & 297.5536 & \\
\hline Sep & 89.6300 & 89.3200 & 1.2531 & 2.1987 & 1.9037 & 30.6338 & 0.7334 & 9.3458 & 19.6063 & 14.0060 & 301.6305 & \\
\hline Oct & 89.0600 & 88.8900 & 1.2718 & 2.4675 & 1.9915 & 31.4969 & 0.7444 & 9.4809 & 19.8995 & 13.1129 & 331.4457 & \\
\hline Nov & 83.2200 & 83.1300 & 1.2041 & 2.3319 & 1.8681 & 30.3210 & 0.7048 & 8.9687 & 18.8402 & 11.8885 & 318.9225 & \\
\hline Dec & 77.9000 & 77.8800 & 1.1043 & 2.2151 & 1.8376 & 28.8236 & 0.6463 & 8.2267 & 17.2778 & 11.5169 & 292.0228 & \\
\hline 2009 Jan & 76.7400 & 76.7600 & 1.0919 & 431 & 1.7708 & 29.7032 & 391 & 367 & 832 & 11.2095 & 506 & \\
\hline Feb & 78.5600 & 78.6900 & 1.1264 & 2.2175 & 1.7953 & 32.0536 & 0.6593 & 8.3931 & 17.6239 & 11.1736 & 335.5791 & \\
\hline Mar & 76.6400 & 76.7800 & 1.0867 & 2.1283 & 1.7920 & 29.5869 & 0.6360 & 8.0964 & 17.0024 & 10.9894 & 330.8110 & \\
\hline Apr & 78.6000 & 78.6300 & 1.1157 & 2.0597 & 1.8025 & 29.8434 & 0.6530 & 8.3107 & 17.4565 & 11.4041 & 328.7061 & 73.5393 \\
\hline May & 80.1600 & 80.1200 & 1.1295 & 2.0149 & 1.7764 & 30.2187 & 0.6611 & 8.4111 & 17.6730 & 11.9591 & 318.4920 & 74.7523 \\
\hline Jun & 83.6600 & 83.6300 & 1.1682 & 2.0401 & 1.8436 & 30.9716 & 0.6837 & 8.6978 & 18.2779 & 12.6848 & 327.5753 & 78.0402 \\
\hline Jul & 83.2400 & 83.1800 & 1.1622 & 2.0339 & 1.8374 & 29.9972 & 0.6802 & 8.6530 & 18.1837 & 12.6836 & 316.4926 & 79.1530 \\
\hline Aug & 83.3750 & 83.3961 & 1.1597 & 1.9808 & 1.7978 & 29.7604 & 0.6788 & 8.6326 & 18.1452 & 12.8190 & 313.0952 & 79.7535 \\
\hline Sep & 80.8586 & 80.7752 & 1.1212 & 1.8949 & 1.7663 & 28.4208 & 0.6562 & 8.3445 & 17.5422 & 12.6550 & 304.6233 & 78.8814 \\
\hline Oct & 79.1104 & 79.0116 & 1.0928 & 1.7870 & 1.7075 & 28.2981 & 0.6396 & 8.1345 & 17.0984 & 12.5543 & 293.4307 & 75.6072 \\
\hline Nov & 80.6685 & 80.5758 & 1.1126 & 1.8044 & 1.7560 & 28.7420 & 0.6512 & 8.2792 & 17.4082 & 12.8631 & 301.3483 & 77.2414 \\
\hline Dec & 80.0717 & 79.9671 & 1.1127 & 1.7988 & 1.7120 & 29.0234 & 0.6513 & 8.2806 & 17.4101 & 12.5894 & 304.1298 & 75.5713 \\
\hline 2010 Jan & 80.6288 & 80.4542 & 1.1327 & 1.7691 & 1.6853 & 29.5959 & 0.6630 & 8.4301 & 17.7227 & 12.5452 & 305.2952 & 74.1788 \\
\hline
\end{tabular}

1 The methodology for this series accounts for changing trade flows over time. An article in the Winter 2004 edition of the Bank of England Quarterly

Bulletin (pages 429-441) provides further information on the calculation of this index.

2 This series is a broad measure of the sterling exchange rate index covering a wider set of countries. An article in the Winter 2004 edition of the Bank of

England Quarterly Bulletin (pages 429-441) provides further information on the calculation of this index.

3 Prior to the January 1999, a synthetic Euro has been calculated by geometrically averaging the bilateral exchange rates of the 11 Euro -area countries using "internal weights"based on each country's share of the extra Euro - area trade. 


\begin{tabular}{|c|c|c|c|c|c|c|c|c|c|c|c|c|c|}
\hline & $\begin{array}{r}\text { Japanese } \\
\text { yen }\end{array}$ & $\begin{array}{r}\text { Latvian } \\
\text { Lats }\end{array}$ & $\begin{array}{r}\text { Lithuanian } \\
\text { Litas }\end{array}$ & $\begin{array}{r}\text { Maltese } \\
\text { Lira } \\
\end{array}$ & $\begin{array}{r}\text { New } \\
\text { Zealand } \\
\text { dollar }\end{array}$ & $\begin{array}{r}\text { Norwegian } \\
\text { kroner }\end{array}$ & $\begin{array}{r}\text { Polish } \\
\text { Zloty }\end{array}$ & $\begin{array}{r}\text { Russian } \\
\text { ruble }\end{array}$ & $\begin{array}{l}\text { South } \\
\text { African } \\
\text { rand }\end{array}$ & $\begin{array}{r}\text { Swedish } \\
\text { kronor }\end{array}$ & $\begin{array}{r}\text { Swiss } \\
\text { franc }\end{array}$ & $\begin{array}{r}\text { Thailand } \\
\text { baht }\end{array}$ & $\begin{array}{r}\text { United } \\
\text { States } \\
\text { dollar } \\
\end{array}$ \\
\hline & AJFO & BK39 & BK36 & BK44 & AJFV & AJFJ & BK47 & BK85 & AJFW & AJFI & AJFD & BK87 & AUSS \\
\hline 2005 & 200.1362 & 1.0185 & 5.0511 & 0.6289 & 2.5821 & 11.7177 & 5.8809 & .. & 11.5711 & 13.5769 & 2.2647 & .. & 1.8197 \\
\hline 2006 & 214.3256 & 1.0215 & 5.0654 & 0.6297 & 2.8412 & 11.8099 & 5.7137 & .. & 12.5004 & 13.5708 & 2.3079 & .. & 1.8429 \\
\hline 2007 & 235.6340 & 1.0235 & 5.0478 & 0.6274 & 2.7220 & 11.7196 & 5.5315 & .. & 14.1099 & 13.5207 & 2.4010 & .. & 2.0018 \\
\hline 2008 & 192.2760 & 0.8844 & 4.3462 & 0.5413 & 2.6056 & 10.3348 & 4.4138 & .. & 15.1347 & 12.0889 & 1.9980 & .. & 1.8528 \\
\hline 2009 & 146.3849 & 0.7930 & 3.8790 & 0.4830 & 2.4864 & 9.8140 & 4.8610 & .. & 13.1089 & 11.9308 & 1.6960 & .. & 1.5651 \\
\hline 2006 Jan & 204.0871 & 1.0150 & 5.0349 & 0.6260 & 2.5733 & 11.7238 & 5.5657 & .. & 10.7447 & 13.5682 & 2.2589 & .. & 1.7678 \\
\hline Feb & 205.9534 & 1.0189 & 5.0539 & 0.6281 & 2.5968 & 11.8013 & 5.5555 & .. & 10.6864 & 13.6719 & 2.2812 & .. & 1.7470 \\
\hline Mar & 204.5284 & 1.0093 & 5.0067 & 0.6223 & 2.7524 & 11.5672 & 5.6298 & .. & 10.8961 & 13.6290 & 2.2763 & .. & 1.7435 \\
\hline Apr & 206.8262 & 1.0024 & 4.9727 & 0.6185 & 2.8438 & 11.2996 & 5.6405 & .. & 10.7565 & 13.4423 & 2.2683 & .. & 1.7685 \\
\hline May & 208.7897 & 1.0189 & 5.0540 & 0.6280 & 2.9666 & 11.4133 & 5.6985 & .. & 11.8373 & 13.6542 & 2.2781 & .. & 1.8702 \\
\hline Jun & 211.2228 & 1.0135 & 5.0274 & 0.6249 & 2.9801 & 11.4433 & 5.8645 & .. & 12.8460 & 13.4493 & 2.2713 & .. & 1.8428 \\
\hline Jul & 213.3904 & 1.0121 & 5.0205 & 0.6243 & 2.9888 & 11.5470 & 5.8022 & .. & 13.0462 & 13.3990 & 2.2816 & .. & 1.8447 \\
\hline Aug & 219.4985 & 1.0291 & 5.1050 & 0.6347 & 2.9864 & 11.8212 & 5.7696 & .. & 13.1493 & 13.6159 & 2.3328 & .. & 1.8944 \\
\hline Sep & 220.7576 & 1.0310 & 5.1141 & 0.6358 & 2.8787 & 12.2424 & 5.8766 & .. & 14.0260 & 13.7324 & 2.3465 & .. & 1.8847 \\
\hline Oct & 222.5697 & 1.0351 & 5.1342 & 0.6383 & 2.8360 & 12.4910 & 5.7969 & .. & 14.3381 & 13.7664 & 2.3643 & .. & 1.8755 \\
\hline Nov & 224.2104 & 1.0340 & 5.1222 & 0.6368 & 2.8578 & 12.2351 & 5.6727 & .. & 13.8577 & 13.5001 & 2.3618 & .. & 1.9119 \\
\hline Dec & 230.0726 & 1.0368 & 5.1309 & 0.6382 & 2.8342 & 12.1339 & 5.6653 & .. & 13.8201 & 13.4210 & 2.3734 & .. & 1.9633 \\
\hline 2007 Jan & 235.9224 & 1.0519 & 5.2067 & 0.6474 & 2.8187 & 12.4809 & 5.8510 & .. & 14.0837 & 13.6935 & 2.4357 & .. & 1.9587 \\
\hline Feb & 235.9113 & 1.0485 & 5.1687 & 0.6426 & 2.8229 & 12.1068 & 5.8320 & .. & 14.0566 & 13.7537 & 2.4267 & .. & 1.9581 \\
\hline Mar & 228.3884 & 1.0424 & 5.0769 & 0.6310 & 2.7854 & 11.9586 & 5.7083 & .. & 14.3187 & 13.6712 & 2.3717 & .. & 1.9471 \\
\hline Apr & 236.7008 & 1.0351 & 5.0803 & 0.6316 & 2.7056 & 11.9479 & 5.6092 & .. & 14.1418 & 13.5889 & 2.4102 & .. & 1.9909 \\
\hline May & 239.6349 & 1.0222 & 5.0677 & 0.6300 & 2.7055 & 11.9516 & 5.5514 & .. & 13.9274 & 13.5121 & 2.4228 & .. & 1.9836 \\
\hline Jun & 243.6641 & 1.0308 & 5.1121 & 0.6354 & 2.6243 & 11.9223 & 5.6301 & .. & 14.2173 & 13.8121 & 2.4498 & .. & 1.9864 \\
\hline Jul & 247.0502 & 1.0328 & 5.1176 & 0.6359 & 2.5880 & 11.7603 & 5.5838 & .. & 14.1834 & 13.6172 & 2.4558 & .. & 2.0338 \\
\hline Aug & 234.7615 & 1.0300 & 5.0970 & 0.6333 & 2.7738 & 11.7670 & 5.6262 & .. & 14.5287 & 13.7633 & 2.4185 & .. & 2.0111 \\
\hline Sep & 232.2151 & 1.0192 & 5.0120 & 0.6231 & 2.8104 & 11.3662 & 5.4969 & .. & 14.3473 & 13.4748 & 2.3932 & .. & 2.0185 \\
\hline Oct & 236.9350 & 1.0103 & 4.9618 & 0.6166 & 2.6906 & 11.0545 & 5.3215 & .. & 13.8304 & 13.1823 & 2.4012 & .. & 2.0446 \\
\hline Nov & 229.6421 & 0.9882 & 4.8706 & 0.6051 & 2.7158 & 11.2138 & 5.1540 & .. & 13.9004 & 13.1059 & 2.3256 & .. & 2.0701 \\
\hline Dec & 226.7818 & 0.9670 & 4.7866 & 0.5947 & 2.6233 & 11.1056 & 4.9894 & .. & 13.7835 & 13.0730 & 2.3004 & .. & 2.0185 \\
\hline 2008 Jan & 212.1604 & 0.9344 & 4.6210 & 0.5755 & 2.5495 & 10.6517 & 4.8299 & .. & 13.8043 & 12.6221 & 2.1679 & .. & 1.9698 \\
\hline Feb & 210.3432 & 0.9279 & 4.5978 & 0.5726 & 2.4644 & 10.5845 & 4.7593 & .. & 15.0434 & 12.4723 & 2.1410 & .. & 1.9638 \\
\hline Mar & 201.9782 & 0.8988 & 4.4530 & 0.5546 & 2.5010 & 10.2910 & 4.5604 & .. & 15.9785 & 12.1329 & 2.0273 & .. & 2.0032 \\
\hline Apr & 203.4441 & 0.8773 & 4.3436 & 0.5409 & 2.5108 & 10.0177 & 4.3298 & .. & 15.3899 & 11.7897 & 2.0093 & .. & 1.9817 \\
\hline May & 204.9599 & 0.8828 & 4.3619 & 0.5432 & 2.5287 & 9.9423 & 4.2990 & .. & 14.9573 & 11.7657 & 2.0524 & .. & 1.9641 \\
\hline Jun & 210.1669 & 0.8887 & 4.3628 & 0.5433 & 2.5831 & 10.0991 & 4.2632 & .. & 15.6108 & 11.8525 & 2.0393 & .. & 1.9658 \\
\hline Jul & 212.3982 & 0.8874 & 4.3558 & 0.5424 & 2.6350 & 10.1504 & 4.1082 & .. & 15.1367 & 11.9299 & 2.0433 & .. & 1.9880 \\
\hline Aug & 206.4774 & 0.8880 & 4.3555 & 0.5424 & 2.6622 & 10.0635 & 4.1497 & .. & 14.4683 & 11.8559 & 2.0445 & .. & 1.8889 \\
\hline Sep & 191.8088 & 0.8847 & 4.3266 & 0.5388 & 2.6659 & 10.2270 & 4.2210 & .. & 14.4827 & 11.9952 & 1.9956 & .. & 1.7986 \\
\hline Oct & 169.3404 & 0.9021 & 4.3913 & 0.5469 & 2.7845 & 10.9368 & 4.5438 & .. & 16.4383 & 12.5372 & 1.9303 & .. & 1.6900 \\
\hline Nov & 148.6274 & 0.8541 & 4.1576 & 0.5178 & 2.7198 & 10.6362 & 4.4978 & .. & 15.5265 & 12.2160 & 1.8258 & .. & 1.5338 \\
\hline Dec & 135.6071 & 0.7823 & 3.8128 & 0.4748 & 2.6620 & 10.4177 & 4.4139 & .. & 14.7801 & 11.8972 & 1.6992 & .. & 1.4859 \\
\hline 2009 Jan & 130.4309 & 0.7690 & 3.7703 & 0.4695 & 2.6303 & 10.0635 & 4.6242 & $\cdot \cdot$ & 14.3458 & 11.7280 & 1.6291 & $\cdot \cdot$ & 1.4452 \\
\hline Feb & 133.7858 & 0.7950 & 3.8893 & 0.4844 & 2.7962 & 9.9050 & 5.2330 & .. & 14.3850 & 12.3113 & 1.6786 & .. & 1.4411 \\
\hline Mar & 138.6818 & 0.7696 & 3.7521 & 0.4673 & 2.6641 & 9.6173 & 5.0268 & .. & 14.1032 & 12.1460 & 1.6378 & .. & 1.4174 \\
\hline Apr & 145.3195 & 0.7913 & 3.8523 & 0.4797 & 2.5779 & 9.8075 & 4.9266 & 49.3331 & 13.2010 & 12.1256 & 1.6900 & 52.1318 & 1.4715 \\
\hline May & 148.9399 & 0.8010 & 3.9001 & 0.4857 & 2.5623 & 9.9471 & 4.9859 & 49.2516 & 12.9391 & 11.9564 & 1.7068 & 53.4151 & 1.5429 \\
\hline Jun & 158.2256 & 0.8192 & 4.0336 & 0.5023 & 2.5636 & 10.4636 & 5.2650 & 50.8640 & 13.1611 & 12.7194 & 1.7700 & 55.8548 & 1.6366 \\
\hline Jul & 154.5546 & 0.8141 & 4.0128 & 0.4997 & 2.5406 & 10.4096 & 4.9905 & 51.5764 & 13.0155 & 12.5799 & 1.7664 & 55.7274 & 1.6366 \\
\hline Aug & 157.1541 & 0.8132 & 4.0043 & 0.4987 & 2.4468 & 10.0488 & 4.7894 & 52.3711 & 13.1550 & 11.8400 & 1.7679 & 56.2828 & 1.6539 \\
\hline Sep & 149.2708 & 0.7894 & 3.8713 & 0.4821 & 2.3213 & 9.6448 & 4.6594 & 50.1975 & 12.2713 & 11.4306 & 1.6984 & 55.2208 & 1.6328 \\
\hline Oct & 146.3149 & 0.7745 & 3.7733 & 0.4699 & 2.1940 & 9.1382 & 4.6046 & 47.6801 & 12.1224 & 11.2636 & 1.6546 & 54.1219 & 1.6199 \\
\hline Nov & 147.9555 & 0.7886 & 3.8417 & 0.4784 & 2.2753 & 9.3627 & 4.6313 & 48.0425 & 12.4563 & 11.4925 & 1.6805 & 55.2344 & 1.6597 \\
\hline Dec & 145.9857 & 0.7874 & 3.8421 & 0.4785 & 2.2644 & 9.3601 & 4.6095 & 48.8620 & 12.1507 & 11.5757 & 1.6714 & 53.9362 & 1.6239 \\
\hline 2010 Jan & 147.2968 & 0.8028 & 3.9111 & 0.4871 & 2.2237 & 9.2717 & 4.6086 & 48.2594 & 12.0525 & 11.5500 & 1.6713 & 53.3903 & 1.6162 \\
\hline
\end{tabular}


Percentage per annum

\begin{tabular}{|c|c|c|c|c|c|c|}
\hline & \multicolumn{3}{|c|}{ Canadian dollar } & \multicolumn{3}{|c|}{ Danish kroner } \\
\hline & \multirow[b]{2}{*}{ Spot } & \multicolumn{2}{|c|}{3 months forward $^{1}$} & \multirow[b]{2}{*}{ Spot } & \multicolumn{2}{|c|}{3 months forward ${ }^{1}$} \\
\hline & & (cents) & percent & & (ore) & percent \\
\hline & AJGD & AJGE & AJGF & AJHE & AJHF & AJHG \\
\hline 2006 Feb & 1.9928 & -0.3025 & -0.6030 & 10.9597 & -4.7799 & -1.7445 \\
\hline Mar & 2.0231 & -0.3050 & -0.6139 & 10.6955 & -4.3235 & -1.6150 \\
\hline Apr & 2.0368 & -0.2226 & -0.4314 & 10.7664 & -4.5492 & -1.6899 \\
\hline May & 2.0604 & -0.1624 & -0.3107 & 10.8664 & -4.6215 & -1.7001 \\
\hline Jun & 2.0565 & -0.1223 & -0.2372 & 10.7885 & -4.1744 & -1.5475 \\
\hline Jul & 2.1104 & -0.2104 & -0.3981 & 10.9182 & -3.9951 & -1.4652 \\
\hline Aug & 2.1106 & -0.3255 & -0.6256 & 11.0833 & -4.2329 & -1.5271 \\
\hline Sep & 2.0842 & -0.3657 & -0.7115 & 10.9987 & -4.1120 & -1.4945 \\
\hline Oct & 2.1369 & -0.4572 & -0.8598 & 11.1373 & -4.1392 & -1.4865 \\
\hline Nov & 2.2461 & -0.5130 & -0.9067 & 11.0630 & -3.9574 & -1.4322 \\
\hline Dec & 2.2770 & -0.5428 & -0.9474 & 11.0636 & -3.7999 & -1.3743 \\
\hline $\mathrm{Feb}$ & 2.2983 & -0.6719 & -1.1652 & 11.0556 & -4.1311 & -1.4937 \\
\hline Mar & 2.2622 & -0.7058 & -1.2566 & 10.9779 & -3.9065 & -1.4244 \\
\hline Apr & 2.2095 & -0.7387 & -1.3394 & 10.9194 & -3.8705 & -1.4176 \\
\hline May & 2.1149 & -0.7314 & -1.3839 & 10.9518 & -3.9195 & -1.4320 \\
\hline Jun & 2.1346 & -0.7181 & -1.3521 & 11.0561 & -4.3110 & -1.5588 \\
\hline Jul & 2.1704 & -0.6857 & -1.2719 & 11.0446 & -4.2684 & -1.5471 \\
\hline Aug & 2.1341 & -0.7352 & -1.3897 & 11.0220 & -5.8978 & -2.1416 \\
\hline Sep & 2.0248 & -0.6158 & -1.2277 & 10.6769 & -4.1419 & -1.5506 \\
\hline Oct & 1.9735 & -0.6909 & -1.4010 & 10.7014 & -4.2236 & -1.5776 \\
\hline Nov & 2.0553 & -0.7065 & -1.3786 & 10.4448 & -4.5734 & -1.7510 \\
\hline Dec & 1.9650 & -0.6227 & -1.2589 & 10.1533 & -3.1692 & -1.2493 \\
\hline 2008 Jan & 2.0045 & -0.7591 & -1.5200 & 10.0104 & -2.7207 & -1.0869 \\
\hline Feb & 1.9432 & -0.9200 & -1.9000 & 9.7635 & -3.0800 & -1.2600 \\
\hline Mar & 2.0390 & -1.0871 & -2.1373 & 9.3534 & -2.6216 & -1.1209 \\
\hline Apr & 1.9946 & -1.1664 & -2.3518 & 9.4910 & -2.2077 & -0.9315 \\
\hline May & 1.9643 & -1.1954 & -2.4490 & 9.4850 & -2.3231 & -0.9779 \\
\hline Jun & 2.0192 & -1.1828 & -2.3366 & 9.4205 & -1.8634 & -0.7898 \\
\hline Sep & 1.8947 & -0.1295 & -0.2751 & 9.4638 & -1.1617 & -0.4905 \\
\hline Oct & 1.9637 & -1.0399 & -2.1224 & 9.4911 & -0.6299 & -0.2655 \\
\hline Nov & 1.9045 & -0.0879 & -0.1848 & 9.0100 & 3.5610 & 1.5809 \\
\hline Dec & 1.7744 & -0.3761 & -0.8478 & 7.6976 & 2.8152 & 1.4612 \\
\hline 2009 Jan & 1.7874 & -0.0664 & -0.1477 & 8.3859 & 2.7462 & 1.3098 \\
\hline Feb & 1.8094 & -0.1038 & -0.2300 & 8.3624 & 2.0706 & 0.9907 \\
\hline Mar & 1.8033 & -0.1378 & -0.3062 & 8.0395 & 1.8862 & 0.9383 \\
\hline Apr & 1.7606 & -0.1334 & 0.3031 & 8.3307 & 1.6821 & 2.8869 \\
\hline May & 1.7668 & -0.1731 & -0.3919 & 8.4817 & 1.5887 & 0.7181 \\
\hline Jun & 1.9126 & -0.1361 & 4.0000 & 8.7421 & 1.0760 & 0.4923 \\
\hline Jul & 1.7934 & -0.1042 & -0.2324 & 8.7075 & 1.2508 & -0.5746 \\
\hline Aug & 1.7670 & -0.0271 & -0.0613 & 8.4455 & 1.3591 & 0.6437 \\
\hline Sep & 1.7168 & -0.0589 & -0.1372 & 8.1449 & 0.8076 & 0.3966 \\
\hline Oct & 1.7744 & -0.0861 & -0.1939 & 8.3118 & 0.9553 & 0.4596 \\
\hline Nov & 1.7302 & -0.0920 & -0.2127 & 8.1349 & 0.7182 & 0.3530 \\
\hline Dec & 1.6931 & -0.0944 & -0.2221 & 8.3749 & 0.4649 & 0.2221 \\
\hline 2010 Jan & 1.7071 & -0.0879 & -0.2062 & 8.5816 & 0.4446 & 0.2074 \\
\hline
\end{tabular}


Percentage per annum

\begin{tabular}{|c|c|c|c|c|c|c|}
\hline & \multicolumn{3}{|c|}{ Japanese yen } & \multicolumn{3}{|c|}{ Norwegian kroner } \\
\hline & \multirow[b]{2}{*}{ Spot } & \multicolumn{2}{|c|}{3 months forward ${ }^{1}$} & \multirow[b]{2}{*}{ Spot } & \multicolumn{2}{|c|}{3 months forward ${ }^{1}$} \\
\hline & & (yen) & percent & & (ore) & percent \\
\hline & AJHQ & AJHR & AJHS & AJHB & AJHC & AJHD \\
\hline 2006 Feb & 202.8124 & -2.2448 & -4.4179 & 11.8184 & -5.8052 & -1.9662 \\
\hline Mar & 204.6190 & -2.2907 & -4.4766 & 11.3825 & -5.2341 & -1.8383 \\
\hline Apr & 207.6224 & -2.3562 & -4.5468 & 11.2305 & -5.1978 & -1.8522 \\
\hline Jun & 211.4049 & -2.2878 & -4.3291 & 11.5070 & -4.9124 & -1.7075 \\
\hline Jul & 213.6896 & -2.3192 & -4.3427 & 11.5157 & -4.8321 & -1.6771 \\
\hline Aug & 223.0811 & -2.5102 & -4.5006 & 11.9914 & -5.0427 & -1.6814 \\
\hline Sep & 220.6157 & -2.5702 & -4.6596 & 12.1769 & -5.0676 & -1.6650 \\
\hline Oct & 223.4402 & -2.6363 & -4.7261 & 12.4765 & -5.2268 & -1.6763 \\
\hline Nov & 227.4836 & -2.6370 & -4.6422 & 12.1159 & -4.7502 & -1.5677 \\
\hline Dec & 233.1961 & -2.6848 & -4.5969 & 12.1871 & -4.2968 & -1.4110 \\
\hline Feb & 232.2012 & -2.8280 & -4.8751 & 12.0400 & -3.7473 & -1.2458 \\
\hline Mar & 231.5511 & -2.7960 & -4.8400 & 11.9698 & -3.3810 & -1.1295 \\
\hline Apr & 238.9841 & -2.9690 & -4.9711 & 11.8921 & -3.5206 & -1.1842 \\
\hline May & 240.9645 & -3.0416 & -5.0465 & 11.9405 & -3.4290 & -1.1491 \\
\hline Jun & 247.8105 & -3.2088 & -5.1800 & 11.8506 & -3.3479 & -1.1000 \\
\hline Jul & 241.9741 & -3.1474 & -5.2073 & 11.8318 & -3.1873 & -1.0786 \\
\hline Aug & 233.8222 & -3.3223 & -5.6796 & 11.7415 & -3.8281 & -1.3049 \\
\hline Sep & 234.3417 & -3.0392 & -5.1890 & 11.0450 & -1.4110 & -0.5109 \\
\hline Oct & 239.5034 & -3.2230 & -5.3779 & 11.1922 & -1.4754 & -0.5290 \\
\hline Nov & 227.9804 & -3.1125 & -5.4566 & 11.4017 & -1.8763 & -0.6596 \\
\hline Dec & 222.3835 & -2.7121 & -4.8745 & 10.8122 & 0.1442 & 0.0518 \\
\hline 2008 Jan & 211.3854 & -2.4528 & -4.6360 & 10.8145 & 0.5424 & 0.1998 \\
\hline Feb & 207.0757 & -2.4300 & -4.6900 & 10.3769 & 0.6800 & 0.2600 \\
\hline Mar & 197.7960 & -2.3949 & -4.8332 & 10.0987 & 1.1260 & 0.4475 \\
\hline Apr & 206.9612 & -2.4644 & -4.7545 & 10.1155 & 2.1103 & 0.8340 \\
\hline May & 208.6274 & -2.5081 & -4.8123 & 10.0790 & 1.7584 & 0.6984 \\
\hline Jun & 210.9705 & -2.5104 & -4.7590 & 10.1463 & 2.2331 & 0.8788 \\
\hline Oct & 158.9301 & -1.3775 & -3.4732 & 10.8778 & 1.9943 & 0.7316 \\
\hline Nov & 146.1611 & -0.5210 & 1.4258 & 10.7452 & 0.6380 & 0.2375 \\
\hline Dec & 130.1747 & -0.4711 & -1.4473 & 10.0832 & 3.9423 & 1.5638 \\
\hline 2009 Jan & 129.4701 & -0.3491 & -1.0782 & 9.9585 & 3.6455 & 1.4644 \\
\hline Feb & 139.4709 & -0.2904 & -0.8317 & 10.0498 & 2.9947 & 1.1920 \\
\hline Mar & 141.5473 & -0.1656 & -0.4691 & 9.6848 & 3.2410 & 1.3386 \\
\hline Apr & 145.7251 & -0.2075 & -0.5696 & 9.7400 & 3.2883 & 1.3504 \\
\hline May & 153.9293 & -0.2056 & -0.5343 & 10.1441 & 2.6200 & 1.0331 \\
\hline Jun & 158.9162 & -0.1970 & -0.4959 & 10.5971 & 2.2781 & 0.8599 \\
\hline Jul & 157.7989 & -0.1742 & -0.4416 & 10.2048 & 2.2212 & 0.8706 \\
\hline Aug & 152.4589 & -0.0990 & -0.2597 & 9.7751 & 2.8188 & 1.1535 \\
\hline Sep & 143.2013 & -0.1237 & -0.3455 & 9.2873 & 2.7037 & 1.1645 \\
\hline Oct & 149.1424 & -0.1547 & -0.3326 & 9.3895 & 2.9798 & 1.2694 \\
\hline Nov & 141.3808 & -0.1474 & -0.4159 & 9.3205 & 2.9827 & 1.2801 \\
\hline Dec & 150.3217 & -0.1564 & -0.4151 & 9.3271 & 3.4464 & 1.4779 \\
\hline 2010 Jan & 145.2373 & -0.1512 & -0.4159 & 9.4362 & 3.5880 & 1.5210 \\
\hline
\end{tabular}




\begin{tabular}{|c|c|c|c|c|c|c|c|c|c|}
\hline & \multicolumn{3}{|c|}{ Swedish kronor } & \multicolumn{3}{|c|}{ Swiss franc } & \multicolumn{3}{|c|}{ US dollar } \\
\hline & \multirow[b]{2}{*}{ Spot } & \multicolumn{2}{|c|}{3 months forward $^{1}$} & \multirow[b]{2}{*}{ Spot } & \multicolumn{2}{|c|}{3 months forward ${ }^{1}$} & \multirow[b]{2}{*}{ Spot } & \multicolumn{2}{|c|}{3 months forward $^{1}$} \\
\hline & & (ore) & percent & & (centimes) & percent & & (cents) & percent \\
\hline & AJGY & AJGZ & AJHA & AJGJ & AJGK & AJGL & LUSS & AJGB & AJGC \\
\hline 2006 Feb & 13.8654 & -8.3464 & -2.4081 & 2.2969 & -1.9326 & -3.3565 & 1.7511 & 0.1500 & 0.3429 \\
\hline Mar & 13.5168 & -7.9227 & -2.3432 & 2.2663 & -1.8832 & -3.3128 & 1.7345 & 0.2000 & 0.4624 \\
\hline Apr & 13.4254 & -8.2028 & -2.4423 & 2.2609 & -1.8494 & -3.2743 & 1.8179 & 0.2400 & 0.5275 \\
\hline May & 13.5036 & -8.1039 & -2.4000 & 2.2733 & -1.8999 & -3.3480 & 1.8712 & 0.2950 & 0.6417 \\
\hline Jun & 13.3205 & -7.4119 & -2.2257 & 2.2657 & -1.7832 & -3.1474 & 1.8494 & 0.3900 & 0.8437 \\
\hline Jul & 13.4827 & -7.5021 & -2.2255 & 2.2990 & -1.8203 & -3.1652 & 1.8671 & 0.3600 & 0.7701 \\
\hline Aug & 13.7625 & -7.5133 & -2.1831 & 2.3453 & -1.8870 & -3.2170 & 1.9018 & 0.2300 & 0.4842 \\
\hline Sep & 13.6929 & -7.5622 & -2.2089 & 2.3427 & -1.8749 & -3.1966 & 1.8682 & 0.1750 & 0.3850 \\
\hline Oct & 13.7779 & -7.5305 & -2.1858 & 2.3727 & -1.9501 & -3.2911 & 1.9073 & 0.1200 & 0.2513 \\
\hline Nov & 13.4559 & -7.1226 & -2.1159 & 2.3569 & -1.8857 & -3.1899 & 1.9670 & 0.0850 & 0.1827 \\
\hline Dec & 13.3937 & -6.8078 & -2.0344 & 2.3895 & -1.8414 & -3.0795 & 1.9570 & 0.0550 & 0.1224 \\
\hline Feb & 13.7501 & -7.4006 & -2.1527 & 2.3934 & -1.9874 & -3.3305 & 1.9600 & -0.0550 & -0.1224 \\
\hline Mar & 13.7602 & -7.3501 & -2.1366 & 2.3946 & -1.9172 & -3.2134 & 1.9613 & -0.0850 & -0.1837 \\
\hline Apr & 13.4166 & -7.1406 & -2.1282 & 2.4132 & -1.9814 & -3.2863 & 1.9997 & -0.1350 & -0.2800 \\
\hline May & 13.6788 & -7.5640 & -2.2105 & 2.4245 & -1.9956 & -3.3058 & 1.9782 & -0.1850 & -0.3838 \\
\hline Jun & 13.7578 & -7.7472 & -2.2529 & 2.4596 & -1.9740 & -3.2000 & 2.0064 & -0.2700 & -0.5373 \\
\hline Jul & 13.6841 & -7.4583 & -2.1813 & 2.4453 & -2.0248 & -3.2980 & 2.0322 & -0.3000 & -0.5911 \\
\hline Aug & 13.8919 & -8.6733 & -2.4968 & 2.4375 & -2.3052 & -3.7869 & 2.0171 & -0.4000 & -0.7921 \\
\hline Sep & 13.1792 & -6.0800 & -1.8452 & 2.3801 & -2.0301 & -3.4118 & 2.0374 & -0.4150 & -0.8235 \\
\hline Oct & 13.2104 & -5.8198 & -1.7623 & 2.4077 & -2.0879 & -3.4689 & 2.0774 & -0.6400 & -1.2308 \\
\hline Nov & 13.1320 & -5.6032 & -1.7060 & 2.3211 & -2.1722 & -3.7414 & 2.0561 & -0.6350 & -1.2427 \\
\hline Dec & 12.8672 & -3.8123 & -1.1841 & 2.2543 & -1.7067 & -3.0400 & 1.9909 & -0.4900 & -0.9849 \\
\hline 2008 Jan & 12.7247 & -3.1769 & -1.0000 & 2.1562 & -1.5284 & -2.8333 & 1.9882 & -1.1450 & -2.3116 \\
\hline Feb & 12.2743 & -2.9000 & -0.9500 & 2.0765 & -1.4900 & -2.8700 & 1.9892 & -1.3100 & -2.6300 \\
\hline Mar & 11.7844 & -2.5195 & -0.8557 & 1.9656 & -1.3896 & -2.8223 & 1.9875 & -1.4250 & -2.8744 \\
\hline Apr & 11.8728 & -1.9296 & -0.6504 & 2.0631 & -1.5059 & -2.9320 & 1.9803 & -1.2850 & -2.6061 \\
\hline May & 11.8653 & -2.2837 & -0.7683 & 2.0645 & -1.5999 & -3.1068 & 1.9762 & -1.4000 & -2.8283 \\
\hline Jun & 11.9700 & -2.2430 & -0.7485 & 2.0273 & -1.5639 & -3.0739 & 1.9901 & -1.3800 & -2.7739 \\
\hline Sep & 12.4271 & 2.7273 & 0.8785 & 1.9977 & -1.0567 & -2.1200 & 1.7821 & 0.5000 & 1.1236 \\
\hline Oct & 12.5964 & -3.5917 & -1.1397 & 1.8861 & -1.1738 & -2.4762 & 1.6158 & -0.7300 & -1.8025 \\
\hline Nov & 12.4295 & 1.2750 & 0.4103 & 1.8643 & 0.9040 & 1.9399 & 1.5345 & 0.0900 & 0.2345 \\
\hline Dec & 11.3810 & -0.8126 & -0.2857 & 1.5298 & -0.4007 & -1.0484 & 1.4376 & -0.2350 & -0.6537 \\
\hline 2009 Jan & 11.9552 & -0.0297 & -0.0100 & 1.6723 & -0.3393 & -0.8110 & 1.4416 & -0.1000 & -0.2774 \\
\hline Feb & 12.8237 & 0.9638 & 0.3007 & 1.6606 & -0.3796 & -0.9151 & 1.4255 & -0.0200 & -0.0561 \\
\hline Mar & 11.8477 & -0.4396 & -0.1485 & 1.6296 & -0.2800 & -0.6871 & 1.4331 & 0.0500 & 0.1396 \\
\hline Apr & 11.9373 & -0.2519 & -0.0844 & 1.6881 & -0.2667 & -0.6320 & 1.4820 & - & - \\
\hline May & 12.2239 & -0.2469 & -0.0808 & 1.7196 & -0.2440 & -0.5676 & 1.6125 & -0.0550 & -0.1364 \\
\hline Jun & 12.7595 & 0.0286 & 0.0090 & 1.7906 & -0.2412 & 0.5388 & 1.6468 & -0.0250 & -0.0607 \\
\hline Jul & 12.0788 & -0.7716 & -0.2555 & 1.7842 & -0.2034 & -0.4560 & 1.6579 & -0.0350 & -0.0849 \\
\hline Aug & 11.5076 & -0.0535 & -0.0186 & 1.7213 & -0.0141 & -0.0328 & 1.6311 & -0.0100 & -0.0245 \\
\hline Sep & 11.1786 & -1.0151 & -0.3632 & 1.6596 & -0.1694 & -0.4083 & 1.5993 & -0.0400 & -0.1000 \\
\hline Oct & 11.6236 & -1.1407 & -0.3926 & 1.6872 & -0.1807 & -0.4292 & 1.6478 & -0.0800 & -0.1942 \\
\hline Nov & 11.4696 & -1.1010 & -0.3840 & 1.6480 & -0.1938 & -0.4709 & 1.6411 & -0.0950 & -0.2316 \\
\hline Dec & 11.5305 & -1.2014 & -0.4166 & 1.6691 & -0.1898 & -0.4554 & 1.6148 & -0.0900 & -0.2229 \\
\hline 2010 Jan & 11.7597 & -0.9228 & -0.3139 & 1.6887 & -0.1987 & -0.4713 & 1.6020 & -0.1050 & -0.2622 \\
\hline
\end{tabular}

1 Forward margins: foreign currency at a premium-/discount+;

Source: Bank of England sterling at a discount-/premium+.

2 Discontinued series due to the introduction of the Euro. 


\section{Interest rate differentials and exchange rates(13.3)}

\begin{tabular}{|c|c|c|c|c|c|c|c|c|c|c|c|c|}
\hline & \multicolumn{6}{|c|}{ Percent per annum } & \multirow{3}{*}{$\begin{array}{r}\text { London gold } \\
\text { price per } \\
\text { fine troy } \\
\text { oz. (p.m. } \\
\text { fixing) } \\
\text { US } \$\end{array}$} & \multicolumn{5}{|c|}{ Exchange rates against } \\
\hline & \multirow{2}{*}{$\begin{array}{r}\text { Interest on } \\
\text { US Treasury } \\
\text { bills } \\
(3 \text { months })\end{array}$} & \multirow{2}{*}{$\begin{array}{r}\text { Interest } \\
\text { on US \$ } \\
\text { deposits in } \\
\text { London } \\
\text { (3 months) }\end{array}$} & \multirow{2}{*}{$\begin{array}{r}\text { Sterling } \\
\text { Interbank } \\
\text { offered } \\
\text { rate in } \\
\text { London } \\
\text { (3 months) }\end{array}$} & \multicolumn{3}{|c|}{$\begin{array}{l}3 \text { month sterling LIBOR } \\
\text { and interest differentials } \\
\text { between the UK and }\end{array}$} & & \multicolumn{3}{|c|}{ Special Drawing Rights of } & \multicolumn{2}{|c|}{ Euro } \\
\hline & & & & Germany & Japan & US & & $£$ Sterling & US \$ & Yen & $£$ sterling & US \$ \\
\hline & LUST & AJIB & AJWR & AJHZ & AJIW & AFBI & AJIF & AJIG & AJIH & DEPL & THAO & THAT \\
\hline 2005 & 3.92 & 4.51 & 4.58 & 2.10 & 4.52 & 0.09 & 513.0000 & 0.8301 & 1.4293 & 168.0390 & 1.4552 & 0.8477 \\
\hline 2006 & 4.89 & 5.34 & 5.28 & 1.57 & 4.72 & -0.05 & 635.7000 & 0.7664 & 1.5044 & 178.8130 & 1.4841 & 0.7584 \\
\hline 2007 & 3.29 & 4.77 & 5.95 & 1.27 & 5.06 & 1.18 & 833.7500 & 0.7888 & 1.5803 & 177.2250 & 1.3619 & 0.6840 \\
\hline 2008 & 0.11 & 1.41 & 2.83 & 0.01 & 2.07 & 1.49 & 869.7500 & 1.0566 & 1.5403 & 139.3020 & 1.0342 & 0.7194 \\
\hline 2009 & 0.05 & 0.48 & 0.63 & 0.05 & 0.42 & 0.22 & 1087.5000 & 0.9680 & 1.5677 & 144.8860 & 1.1255 & 0.6970 \\
\hline 2006 Jan & 4.37 & 4.69 & 4.53 & 1.99 & 4.47 & -0.15 & 568.7500 & 0.8160 & 1.4454 & 169.2850 & 1.4639 & 0.8236 \\
\hline Feb & 4.51 & 4.81 & 4.52 & 1.87 & 4.44 & -0.28 & 556.0000 & 0.8217 & 1.4350 & 166.9080 & 1.4688 & 0.8388 \\
\hline Mar & 4.52 & 4.98 & 4.55 & 1.74 & 4.45 & -0.42 & 582.0000 & 0.8305 & 1.4409 & 169.6310 & 1.4332 & 0.8263 \\
\hline Apr & 4.66 & 5.10 & 4.62 & 1.78 & 4.52 & -0.47 & 644.0000 & 0.8134 & 1.4711 & 167.9510 & 1.4432 & 0.7939 \\
\hline Jun & 4.88 & 5.46 & 4.72 & 1.67 & 4.38 & -0.73 & 613.5000 & 0.8065 & 1.4794 & 169.5650 & 1.4463 & 0.7820 \\
\hline Jul & 4.97 & 5.43 & 4.74 & 1.58 & 4.33 & -0.69 & 632.5000 & 0.7959 & 1.4839 & 169.8290 & 1.4631 & 0.7836 \\
\hline Aug & 4.92 & 5.37 & 4.95 & 1.69 & 4.55 & -0.42 & 623.5000 & 0.7803 & 1.4885 & 174.3500 & 1.4858 & 0.7813 \\
\hline Sep & 4.77 & 5.33 & 5.04 & 1.63 & 4.62 & -0.28 & 599.2500 & 0.7894 & 1.4764 & 174.1540 & 1.4749 & 0.7895 \\
\hline Oct & 4.95 & 5.35 & 5.15 & 1.59 & 4.72 & -0.19 & 603.7500 & 0.7795 & 1.4800 & 174.4670 & 1.4943 & 0.7835 \\
\hline Nov & 4.90 & 5.33 & 5.21 & 1.58 & 4.71 & -0.11 & 646.7000 & 0.7707 & 1.5077 & 175.2590 & 1.4840 & 0.7544 \\
\hline Dec & 4.89 & 5.34 & 5.28 & 1.57 & 4.72 & -0.05 & 635.7000 & 0.7664 & 1.5044 & 178.8130 & 1.4841 & 0.7584 \\
\hline 2007 Jan & 4.99 & 5.32 & 5.55 & 1.77 & 5.03 & 0.23 & 650.5000 & 0.7632 & 1.4902 & 181.0830 & 1.5063 & 0.7695 \\
\hline Feb & 5.01 & 5.30 & 5.49 & 1.65 & 4.79 & 0.20 & 664.2000 & 0.7690 & 1.5047 & 178.4000 & 1.4836 & 0.7569 \\
\hline Mar & 4.91 & 5.31 & 5.57 & 1.65 & 4.91 & 0.27 & 661.7500 & 0.7713 & 1.5102 & 178.2780 & 1.4733 & 0.7512 \\
\hline Apr & 4.79 & 5.33 & 5.68 & 1.68 & 5.03 & 0.37 & 677.0000 & 0.7642 & 1.5242 & 182.2310 & 1.4654 & 0.7328 \\
\hline May & 4.60 & 5.34 & 5.77 & 1.66 & 5.09 & 0.44 & 659.1000 & 0.7651 & 1.5129 & 184.0230 & 1.4702 & 0.7432 \\
\hline Jun & 4.68 & 5.35 & 5.96 & 1.81 & 5.22 & 0.64 & 650.5000 & 0.7559 & 1.5156 & 187.0210 & 1.4857 & 0.7405 \\
\hline Jul & 4.82 & 5.33 & 6.01 & 1.76 & 5.24 & 0.69 & 665.5000 & 0.7538 & 1.5312 & 182.7370 & 1.4843 & 0.7304 \\
\hline Aug & 3.91 & 5.61 & 6.60 & 1.91 & 5.68 & 1.04 & 672.0000 & 0.7588 & 1.5326 & 178.5210 & 1.4795 & 0.7335 \\
\hline Sep & 3.62 & 5.33 & 6.23 & 1.49 & 5.25 & 0.95 & 743.0000 & 0.7663 & 1.5567 & 179.4660 & 1.4324 & 0.7030 \\
\hline 2008 Jan & 1.92 & 3.06 & 5.54 & 1.20 & 4.71 & 2.53 & 923.2500 & 0.8000 & 1.5953 & 169.4020 & 1.3428 & 0.6754 \\
\hline Feb & 1.81 & 2.96 & 5.70 & 1.33 & 4.76 & 2.76 & 971.5000 & 0.8120 & 1.6106 & 167.8680 & 1.3104 & 0.6588 \\
\hline Mar & 1.36 & 3.00 & 5.99 & 1.29 & 5.11 & 3.03 & 933.5000 & 0.8270 & 1.6445 & 163.8740 & 1.2543 & 0.6311 \\
\hline Apr & 1.44 & 3.06 & 5.80 & 0.98 & 4.92 & 2.79 & 871.0000 & 0.8256 & 1.6238 & 169.1170 & 1.2718 & 0.6422 \\
\hline May & 1.85 & 2.98 & 5.84 & 1.01 & 4.95 & 2.90 & 885.7500 & 0.8212 & 1.6207 & 170.9830 & 1.2716 & 0.6435 \\
\hline Jun & 1.87 & 2.99 & 5.91 & 0.99 & 5.01 & 2.95 & 930.2500 & 0.8202 & 1.6336 & 172.2980 & 1.2632 & 0.6347 \\
\hline Jul & 1.67 & 2.86 & 5.77 & 0.83 & 4.89 & 2.93 & 918.0000 & 0.8200 & 1.6200 & 175.4500 & 1.2696 & 0.6409 \\
\hline Aug & 1.69 & 2.99 & 5.73 & 0.79 & 4.87 & 2.77 & 832.5000 & 0.8584 & 1.5699 & 170.7560 & 1.2388 & 0.6793 \\
\hline Sep & 0.90 & 5.32 & 6.23 & 1.03 & 5.29 & 0.98 & 884.5000 & 0.8652 & 1.5572 & 163.6480 & 1.2684 & 0.7117 \\
\hline Oct & 0.44 & 2.85 & 5.93 & 1.23 & 5.06 & 3.15 & 730.7500 & 0.9202 & 1.4883 & 145.1990 & 1.2745 & 0.7888 \\
\hline Nov & 0.01 & 3.78 & 3.98 & 0.25 & 3.17 & 0.33 & 814.5000 & 0.9702 & 1.4880 & 141.7890 & 1.2095 & 0.7882 \\
\hline Dec & 0.11 & 1.41 & 2.83 & 0.01 & 2.07 & 1.49 & 869.7500 & 1.0566 & 1.5403 & 139.3020 & 1.0342 & 0.7194 \\
\hline 2009 Jan & 0.24 & 1.58 & 2.13 & 0.16 & 1.58 & 0.68 & 919.5000 & 1.0432 & 1.4919 & 133.7800 & 1.1249 & 0.7803 \\
\hline Feb & 0.26 & 1.60 & 2.05 & 0.32 & 1.51 & 0.56 & 952.0000 & 1.0337 & 1.4674 & 143.3330 & 1.1224 & 0.7874 \\
\hline Mar & 0.13 & 1.16 & 1.65 & 0.19 & 1.10 & 0.54 & 916.5000 & 1.0426 & 1.4951 & 147.1300 & 1.0794 & 0.7532 \\
\hline Apr & 0.14 & 1.35 & 1.38 & 0.09 & 0.90 & 0.10 & 883.2500 & 1.0104 & 1.4978 & 147.0270 & 1.1184 & 0.7547 \\
\hline May & 0.14 & 0.77 & 1.23 & 0.03 & 0.78 & 0.53 & 975.5000 & 0.9584 & 1.5481 & 148.2880 & 1.1392 & 0.7065 \\
\hline Jun & 0.20 & 0.92 & 1.18 & 0.11 & 0.75 & 0.28 & 934.5000 & 0.9373 & 1.5522 & 148.9670 & 1.1739 & 0.7129 \\
\hline Jul & 0.18 & 0.66 & 0.90 & 0.04 & 0.49 & 0.24 & 939.0000 & 0.9377 & 1.5533 & 148.6070 & 1.1694 & 0.7054 \\
\hline Aug & 0.15 & 0.36 & 0.70 & -0.10 & 0.31 & 0.34 & 955.5000 & 0.9580 & 1.5639 & 146.8210 & 1.1348 & 0.6957 \\
\hline Sep & 0.14 & 0.58 & 0.58 & -0.11 & 0.25 & 0.02 & 995.7500 & 0.9833 & 1.5844 & 141.7850 & 1.0941 & 0.6841 \\
\hline Oct & 0.07 & 0.51 & 0.60 & 0.03 & 0.37 & 0.19 & 1040.0000 & 0.9624 & 1.5899 & 145.0300 & 1.1168 & 0.6778 \\
\hline Nov & 0.06 & 0.28 & 0.60 & 0.02 & 0.40 & 0.42 & 1175.7500 & 0.9775 & 1.6102 & 139.0710 & 1.0931 & 0.6661 \\
\hline Dec & 0.05 & 0.48 & 0.63 & 0.05 & 0.42 & 0.22 & 1087.5000 & 0.9680 & 1.5677 & 144.8860 & 1.1255 & 0.6970 \\
\hline 2010 Jan & 0.08 & 0.46 & 0.60 & 0.09 & 0.45 & 0.24 & 1078.5000 & 0.9631 & 1.5542 & 140.2500 & 1.1525 & 0.7194 \\
\hline
\end{tabular}




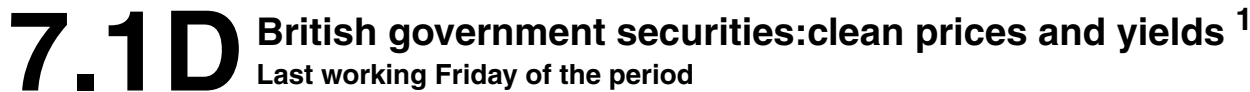

\begin{tabular}{|c|c|c|c|c|c|c|}
\hline & \multicolumn{2}{|c|}{$\begin{array}{l}\text { Principal } \\
\text { Strip } \\
7 \text { June } 2021\end{array}$} & \multicolumn{2}{|c|}{$\begin{array}{c}\text { Principal } \\
\text { Strip } \\
7 \text { March } 2025\end{array}$} & \multicolumn{2}{|c|}{$\begin{array}{c}\text { Principal } \\
\text { Strip } \\
7 \text { June } 2032\end{array}$} \\
\hline & Price $£$ & $\begin{array}{l}\text { Gross redemption } \\
\text { yield \% per annum }\end{array}$ & Price $£$ & $\begin{array}{l}\text { Gross redemption } \\
\text { yield \% per annum }\end{array}$ & Price $£$ & $\begin{array}{l}\text { Gross redemption } \\
\text { yield \% per annum }\end{array}$ \\
\hline \multicolumn{7}{|c|}{ Clean prices and yields ${ }^{1}$} \\
\hline $\begin{array}{c}2008 \text { Feb } \\
\text { Mar } \\
\text { Apr } \\
\text { May } \\
\text { Jun }\end{array}$ & $\begin{array}{r}\text { GPVK } \\
54.35 \\
53.85 \\
52.15 \\
51.60 \\
51.76\end{array}$ & $\begin{array}{l}\text { GPVL } \\
4.650 \\
4.750 \\
5.029 \\
5.148 \\
5.156\end{array}$ & $\begin{array}{l}\text { OEVO } \\
46.46 \\
45.88 \\
44.39 \\
43.92 \\
43.98\end{array}$ & $\begin{array}{l}\text { OEVP } \\
4.557 \\
4.654 \\
4.875 \\
4.969 \\
4.983\end{array}$ & $\begin{array}{r}\text { GPVN } \\
34.660 \\
34.420 \\
33.140 \\
33.130 \\
33.280\end{array}$ & $\begin{array}{r}\text { GPVO } \\
4.415 \\
4.459 \\
4.633 \\
4.653 \\
4.649\end{array}$ \\
\hline $\begin{array}{l}\text { Jul } \\
\text { Aug } \\
\text { Sep } \\
\text { Oct } \\
\text { Nov } \\
\text { Dec }\end{array}$ & $\begin{array}{l}51.88 \\
55.08 \\
54.75 \\
54.52 \\
59.15 \\
63.05\end{array}$ & $\begin{array}{l}5.169 \\
4.727 \\
4.805 \\
4.876 \\
4.239 \\
3.735\end{array}$ & $\begin{array}{l}44.01 \\
46.41 \\
45.77 \\
44.29 \\
47.14 \\
50.22\end{array}$ & $\begin{array}{l}5.001 \\
4.703 \\
4.810 \\
5.045 \\
4.677 \\
4.295\end{array}$ & $\begin{array}{l}33.180 \\
34.070 \\
33.500 \\
91.760 \\
34.680 \\
37.920\end{array}$ & $\begin{array}{l}4.677 \\
4.487 \\
4.670 \\
4.839 \\
4.554 \\
4.176\end{array}$ \\
\hline $\begin{array}{r}2009 \text { Jan } \\
\text { Feb } \\
\text { Mar } \\
\text { Apr } \\
\text { May } \\
\text { Jun }\end{array}$ & $\begin{array}{l}59.50 \\
61.39 \\
64.52 \\
62.47 \\
61.37 \\
62.26\end{array}$ & $\begin{array}{l}4.250 \\
4.017 \\
3.628 \\
3.926 \\
4.105 \\
4.010\end{array}$ & $\begin{array}{l}47.04 \\
47.26 \\
51.75 \\
49.05 \\
48.68 \\
49.82\end{array}$ & $\begin{array}{l}4.742 \\
4.735 \\
4.178 \\
4.545 \\
4.619 \\
4.492\end{array}$ & $\begin{array}{l}33.240 \\
33.790 \\
37.810 \\
35.540 \\
34.730 \\
35.510\end{array}$ & $\begin{array}{l}4.774 \\
4.718 \\
4.239 \\
4.529 \\
4.648 \\
4.565\end{array}$ \\
\hline $\begin{array}{l}\text { Jul } \\
\text { Aug } \\
\text { Sep } \\
\text { Oct } \\
\text { Nov } \\
\text { Dec }\end{array}$ & $\begin{array}{l}61.80 \\
63.68 \\
62.68 \\
62.84 \\
63.62 \\
62.16\end{array}$ & $\begin{array}{l}4.105 \\
3.873 \\
4.036 \\
4.046 \\
3.960 \\
4.192\end{array}$ & $\begin{array}{l}48.58 \\
53.13 \\
53.14 \\
52.18 \\
52.09 \\
50.95\end{array}$ & $\begin{array}{l}4.682 \\
4.117 \\
4.137 \\
4.284 \\
4.320 \\
4.484\end{array}$ & $\begin{array}{l}34.330 \\
38.990 \\
39.230 \\
38.520 \\
38.590 \\
37.586\end{array}$ & $\begin{array}{l}4.735 \\
4.180 \\
4.166 \\
4.267 \\
4.273 \\
4.404\end{array}$ \\
\hline 2010 Jan & 61.44 & 4.340 & 50.19 & 4.620 & 36.720 & \\
\hline
\end{tabular}

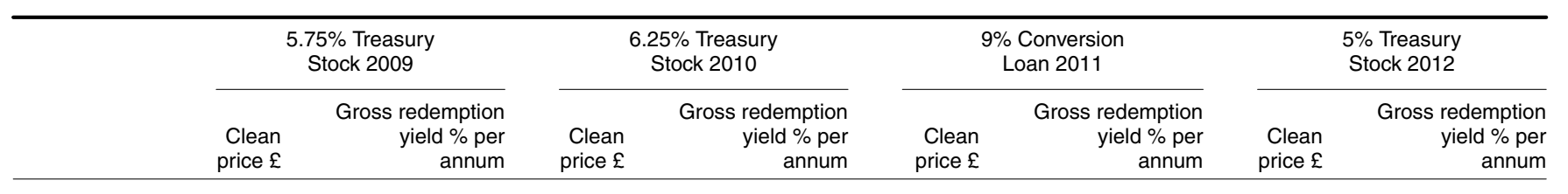

Clean prices and yields ${ }^{1}$

$\begin{array}{cr} & \\ 2008 \text { Feb } & \text { IDZQ } \\ \text { Mar } & 102.85 \\ \text { Apr } & 93.12 \\ \text { May } & 101.09 \\ \text { Jun } & 100.92 \\ & \\ \text { Jul } & 93.53 \\ \text { Aug } & 101.39 \\ \text { Sep } & 101.90 \\ \text { Oct } & 103.32 \\ \text { Nov } & 104.04 \\ \text { Dec } & 104.91 \\ & \\ 2009 \text { Jan } & 104.47 \\ \text { Feb } & 103.94 \\ \text { Mar } & 99.69 \\ \text { Apr } & 99.73 \\ \text { May } & 99.71 \\ \text { Jun } & 102.23 \\ & \\ \text { Jul } & 101.85 \\ \text { Aug } & 101.43 \\ \text { Sep } & 101.04 \\ \text { Oct } & 99.96 \\ \text { Nov } & 100.00 \\ \text { Dec } & \\ & \end{array}$

2010 Jan

$\begin{array}{rr}\text { IDKW } & \text { IDKX } \\ 4.054 & 105.76 \\ 3.999 & 105.70 \\ 4.477 & 104.26 \\ 4.994 & 102.93 \\ 5.075 & 102.67 \\ & \\ 4.980 & 102.95 \\ 4.632 & 103.84 \\ 4.090 & 104.25 \\ 2.645 & 106.75 \\ 1.724 & 107.94 \\ 0.606 & 109.54 \\ 0.894 & 109.28 \\ 0.589 & 109.03 \\ 0.458 & 108.77 \\ 0.452 & 108.45 \\ 0.563 & 108.03 \\ 0.601 & 107.27 \\ & \\ 0.366 & 107.04 \\ 0.345 & 106.90 \\ 0.304 & 106.51 \\ 0.451 & 105.87 \\ - & 105.50 \\ . . & 105.32 \\ . . & 104.58\end{array}$

$\begin{array}{lr}\text { IDKY } & \text { IDKZ } \\ 3.997 & 115.120 \\ 3.961 & 115.090 \\ 4.478 & 112.800 \\ 4.978 & 111.090 \\ 5.053 & 110.640 \\ & \\ 4.888 & 110.800 \\ 4.420 & 111.940 \\ 4.164 & 112.200 \\ 2.851 & 114.410 \\ 2.140 & 115.700 \\ 1.221 & 117.180 \\ & \\ 1.057 & 117.750 \\ 0.978 & 117.470 \\ 0.881 & 117.480 \\ 0.809 & 116.650 \\ 0.786 & 115.980 \\ 1.005 & 114.800 \\ & \\ 0.833 & 114.330 \\ 0.614 & 114.460 \\ 0.598 & 114.170 \\ 0.695 & 113.210 \\ 0.646 & 112.930 \\ 0.497 & 112.650 \\ 0.588 & 111.570\end{array}$

$\begin{array}{lr}\text { IDOJ } & \text { GPVQ } \\ 4.131 & 104.22 \\ 4.042 & 103.58 \\ 4.652 & 101.65 \\ 5.095 & 100.19 \\ 5.164 & 99.72 \\ & \\ 5.022 & 100.20 \\ 4.502 & 101.87 \\ 4.300 & 102.16 \\ 3.350 & 104.34 \\ 2.740 & 106.04 \\ 2.066 & 107.70 \\ & \\ 1.563 & 109.37 \\ 1.456 & 109.06 \\ 1.209 & 108.48 \\ 1.294 & 108.43 \\ 1.307 & 108.24 \\ 1.565 & 107.15 \\ & \\ 1.480 & 107.11 \\ 1.127 & 107.94 \\ 0.984 & 108.31 \\ 1.101 & 107.76 \\ 0.923 & 108.02 \\ 0.821 & 107.98 \\ 0.919 & 107.21\end{array}$

GPVR
4.158
4.007
4.528
4.941
5.082

4.937
4.420
4.317
3.609
3.041
2.486
2.320
1.893
2.007
1.945
1.926
2.240

2.167
1.760
1.520
1.614
1.394
1.323
1.489

Nominal amount outstanding at end of year: $£$ million

\begin{tabular}{|c|c|c|c|c|}
\hline $\begin{array}{l}2008 \\
2009\end{array}$ & $\begin{array}{r}\text { IDLF } \\
14096 \\
. .\end{array}$ & $\begin{array}{l}\text { IDLG } \\
6111 \\
6720\end{array}$ & $\begin{array}{l}\text { IDLH } \\
6650 \\
7312\end{array}$ & $\begin{array}{l}\text { GPVS } \\
24433 \\
26867\end{array}$ \\
\hline $\begin{array}{l}1 \mathrm{Cl} \\
2 \mathrm{Dc} \\
\mathrm{m}\end{array}$ & $\begin{array}{l}\text { des accr } \\
\text { nber } 199 \\
\text { D), whilst }\end{array}$ & UK D & & Source: UK Debt Management Office \\
\hline
\end{tabular}




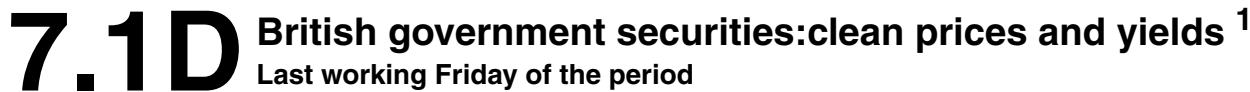

continued

\begin{tabular}{|c|c|c|c|c|c|c|c|c|c|c|c|c|c|}
\hline \multicolumn{2}{|c|}{$\begin{array}{c}\text { 8\% Treasury } \\
\text { Stock } 2015\end{array}$} & \multicolumn{2}{|c|}{$\begin{array}{l}\text { 8.75\% Treasury } \\
\text { Stock } 2017\end{array}$} & \multicolumn{2}{|c|}{$\begin{array}{l}\text { 8\% Treasury } \\
\text { Stock } 2021\end{array}$} & \multicolumn{2}{|c|}{$\begin{array}{c}\text { 6\% Treasury } \\
\text { Stock } 2028\end{array}$} & \multicolumn{2}{|c|}{$\begin{array}{l}4.25 \% \text { Treasury } \\
\text { Stock } 2032\end{array}$} & \multicolumn{2}{|c|}{$\begin{array}{l}4.75 \% \text { Treasury } \\
\text { Stock } 2038\end{array}$} & \multicolumn{2}{|c|}{$\begin{array}{l}\text { 4.25\% Treasury } \\
\text { Gilt } 2055\end{array}$} \\
\hline $\begin{array}{r}\text { Clean } \\
\text { price } £\end{array}$ & $\begin{array}{r}\text { Gross } \\
\text { redempti- } \\
\text { on yield } \\
\% \text { per } \\
\text { annum. }\end{array}$ & $\begin{array}{l}\text { Clean } \\
\text { price } £\end{array}$ & $\begin{array}{l}\text { Gross } \\
\text { redempti- } \\
\text { on yield } \\
\% \text { per } \\
\text { annum. }\end{array}$ & $\begin{array}{l}\text { Clean } \\
\text { price } £\end{array}$ & $\begin{array}{l}\text { Gross } \\
\text { redempti- } \\
\text { on yield } \\
\% \text { per } \\
\text { annum. }\end{array}$ & $\begin{array}{l}\text { Clean } \\
\text { price } £\end{array}$ & $\begin{array}{r}\text { Gross } \\
\text { redempti- } \\
\text { on yield } \\
\% \text { per } \\
\text { annum. }\end{array}$ & $\begin{array}{l}\text { Clean } \\
\text { price } £\end{array}$ & $\begin{array}{r}\text { Gross } \\
\text { redempti- } \\
\text { on yield } \\
\% \text { per } \\
\text { annum. }\end{array}$ & $\begin{array}{c}\text { Clean } \\
\text { price } £\end{array}$ & $\begin{array}{r}\text { Gross } \\
\text { redempti- } \\
\text { on yield } \\
\% \text { per } \\
\text { annum }\end{array}$ & $\begin{array}{l}\text { Clean } \\
\text { price } £\end{array}$ & $\begin{array}{r}\text { Gross } \\
\text { redempti- } \\
\text { on yield } \\
\% \text { per } \\
\text { annum }\end{array}$ \\
\hline
\end{tabular}

Clean prices and yields ${ }^{1}$

$\begin{array}{crrr}2008 \text { Feb } & \text { IDWZ } & \text { IDZC } & \text { AJRG } \\ \text { Mar } & 122.98 & 4.463 & 132.290 \\ \text { Apr } & 120.56 & 4.296 & 132.680 \\ \text { May } & 118.39 & 5.748 & 128.760 \\ \text { Jun } & 117.20 & 5.183 & 126.560 \\ & & & \\ \text { Jul } & 117.80 & 5.071 & 126.370 \\ \text { Aug } & 121.13 & 4.550 & 130.350 \\ \text { Sep } & 120.83 & 4.566 & 129.850 \\ \text { Oct } & 121.46 & 4.439 & 129.880 \\ \text { Nov } & 125.90 & 3.765 & 135.870 \\ \text { Dec } & 128.95 & 3.308 & 140.190 \\ & & & \\ \text { 2009 Jan } & 127.07 & 3.514 & 135.360 \\ \text { Feb } & 129.51 & 3.126 & 138.570 \\ \text { Mar } & 133.00 & 2.590 & 143.520 \\ \text { Apr } & 131.59 & 2.736 & 140.380 \\ \text { May } & 131.47 & 2.700 & 138.940 \\ \text { Jun } & 129.48 & 2.938 & 139.280 \\ & & & \\ \text { Jul } & 127.39 & 3.195 & 136.710 \\ \text { Aug } & 129.35 & 2.850 & 138.710 \\ \text { Sep } & 128.97 & 2.859 & 137.670 \\ \text { Oct } & 127.91 & 2.961 & 137.740 \\ \text { Nov } & 128.00 & 2.897 & 138.000 \\ \text { Dec } & 127.58 & 2.925 & 136.050\end{array}$

$\begin{array}{lrrr}\text { AJRH } & \text { IDZD } & \text { IHZG } & \text { IHZH } \\ 4.524 & 133.730 & 4.578 & 119.480 \\ 4.457 & 133.030 & 4.625 & 118.410 \\ 4.874 & 129.230 & 4.950 & 115.240 \\ 5.104 & 127.290 & 5.104 & 113.600 \\ 5.213 & 126.770 & 5.141 & 113.180 \\ & & & \\ 5.086 & 126.850 & 5.123 & 113.390 \\ 4.588 & 131.940 & 4.652 & 117.610 \\ 4.622 & 130.990 & 4.724 & 116.300 \\ 4.587 & 131.070 & 4.702 & 114.290 \\ 3.869 & 138.400 & 4.057 & 119.940 \\ 3.368 & 144.560 & 3.544 & 126.260 \\ & & & \\ 3.860 & 138.630 & 4.002 & 119.310 \\ 3.465 & 141.660 & 3.735 & 120.460 \\ 2.881 & 146.100 & 3.358 & 127.860 \\ 3.186 & 142.390 & 3.638 & 122.860 \\ 3.308 & 140.190 & 3.802 & 121.580 \\ 3.230 & 140.400 & 3.766 & 123.110 \\ & & & \\ 3.486 & 139.040 & 3.861 & 120.000 \\ 3.212 & 141.630 & 3.622 & 129.240 \\ 3.298 & 140.080 & 3.736 & 128.030 \\ 3.242 & 139.540 & 3.761 & 125.660 \\ 3.171 & 140.270 & 3.680 & 125.760 \\ 3.380 & 137.720 & 3.889 & 123.430 \\ 3.804 & 135.710 & 4.044 & 121.420\end{array}$

$\begin{array}{rr}\text { IHZI } & \text { IHZJ } \\ 4.540 & 96.97 \\ 4.609 & 96.49 \\ 4.824 & 93.50 \\ 4.938 & 92.36 \\ 4.966 & 92.06 \\ & \\ 4.948 & 92.03 \\ 4.648 & 95.50 \\ 4.737 & 93.67 \\ 4.876 & 91.76 \\ 4.481 & 97.27 \\ 4.066 & 103.12 \\ & \\ 4.516 & 95.69 \\ 4.434 & 96.74 \\ 3.950 & 103.43 \\ 4.267 & 99.27 \\ 4.348 & 97.66 \\ 4.242 & 98.79 \\ & \\ 4.447 & 96.26 \\ 3.838 & 103.82 \\ 3.906 & 103.42 \\ 4.056 & 101.96 \\ 4.045 & 102.15 \\ 4.196 & 100.17 \\ & \\ 4.326 & 98.11\end{array}$

BMCY A5FN

4.455106 .14

4.489106 .03

$\begin{array}{ll}4.703 & 103.06 \\ 4.789 & 102.71\end{array}$

$\begin{array}{ll}4.789 & 102.71 \\ 4.812 & 102.25\end{array}$

E7S4

$4.384 \quad 100.12$

$100.79-4.244$

$\begin{array}{lll}4.563 & 98.61 & 4.319\end{array}$

$\begin{array}{lll}4.584 & 15.91 & 3.906 \\ 4.612 & 98.57 & 4.321\end{array}$

$4.815 \quad 102.10$

\begin{tabular}{ll}
$4.620 \quad 98.08$ \\
\hline
\end{tabular}

$4.562 \quad 106.15$

$\begin{array}{ll}4.695 & 103.56 \\ 4.839 & 103.88\end{array}$

$4.438 \quad 110.82$

$4.381 \quad 100.97$

$\begin{array}{ll}4.532 & 96.76\end{array}$

$\begin{array}{rr}4.119 & 105.21\end{array}$

4.345

$4.043 \quad 116.43$

3.824111 .05

$4.551 \quad 105.83$

$4.477 \quad 106.95$

$4.021 \quad 109.88$

$\begin{array}{ll}4.230 & 106.62 \\ 4.413 & 102.98\end{array}$

$\begin{array}{ll}4.413 & 102.98 \\ 4.334 & 105.84\end{array}$

$4.379 \quad 98.74$

$4.332 \quad 98.93$

$4.167 \quad 98.57$

$\begin{array}{ll}4.350 & 98.16 \\ 4.565 & 93.98\end{array}$

$\begin{array}{ll}4.565 & 93.98 \\ 4.394 & 98.19\end{array}$

4.414

4.313

3.748

$4.514 \quad 103.99$

$4.503 \quad 96.48$

$3.993 \quad 110.55$

$\begin{array}{ll}4.019 & 110.80 \\ 4.116 & 110.32\end{array}$

$\begin{array}{ll}4.125 & 103.48\end{array}$

$\begin{array}{ll}4.111 & 103.75 \\ 4.137 & 103.31\end{array}$

$4.114 \quad 104.40$

$\begin{array}{ll}4.103 & 110.71 \\ 4.238 & 108.87\end{array}$

$4.217 \quad 103.32$

4.313

2010 Jan

125.91

$3.116 \quad 134.270$

$3.804 \quad 135.710$

$4.383 \quad 106.05$

$4.378 \quad 99.57$

4.303

4.321

4.342
4.563

4.341

4.430

4.082
4.069

4.090

4.039
4.089

Nominal amount outstanding at end of year: $£$ million

\begin{tabular}{|c|c|c|c|c|c|c|c|c|c|c|c|c|c|c|}
\hline \multirow[t]{2}{*}{$\begin{array}{l}2008 \\
2009\end{array}$} & \multicolumn{2}{|l|}{$\begin{array}{r}\text { IDLI } \\
9092 \\
9998\end{array}$} & \multicolumn{2}{|l|}{$\begin{array}{r}\text { AJPS } \\
9551 \\
10502\end{array}$} & \multicolumn{2}{|l|}{$\begin{array}{r}\text { IDLJ } \\
20631 \\
22686\end{array}$} & \multicolumn{2}{|c|}{$\begin{array}{r}\text { IDLK } \\
14489 \\
16932\end{array}$} & \multicolumn{2}{|c|}{$\begin{array}{r}\text { IDLL } \\
20342 \\
24618\end{array}$} & \multicolumn{2}{|l|}{$\begin{array}{r}\text { A5FP } \\
17561 \\
20227\end{array}$} & \multicolumn{2}{|l|}{$\begin{array}{r}\text { E7S6 } \\
17413 \\
20147\end{array}$} \\
\hline & \multicolumn{2}{|c|}{$\begin{array}{l}2.5 \% \text { Consolidated } \\
\text { Stock }\end{array}$} & \multicolumn{2}{|c|}{ 3.5\% War Loan } & \multicolumn{2}{|c|}{$\begin{array}{l}2.5 \% \text { Treasury }{ }^{2} \\
\text { Index-linked } 2011\end{array}$} & \multicolumn{2}{|c|}{$\begin{array}{l}2.5 \% \text { Treasury }^{2} \\
\text { Index-linked } 2016\end{array}$} & \multicolumn{2}{|c|}{$\begin{array}{l}2.5 \% \text { Treasury }^{2} \\
\text { Index-linked } 2024\end{array}$} & \multicolumn{2}{|c|}{$\begin{array}{c}2 \% \text { Treasury }^{2} \\
\text { Index-linked } 2035\end{array}$} & \multicolumn{2}{|c|}{$\begin{array}{c}1.25 \% \text { Treasury } \\
\text { Index-linked } 2055\end{array}$} \\
\hline & $\begin{array}{l}\text { Clean } \\
\text { price } £\end{array}$ & $\begin{array}{r}\text { Gross } \\
\text { redempti- } \\
\text { on yield } \\
\% \text { per } \\
\text { annum. }\end{array}$ & $\begin{array}{l}\text { Clean } \\
\text { price } £\end{array}$ & $\begin{array}{l}\text { Gross } \\
\text { redempti- } \\
\text { on yield } \\
\% \text { per } \\
\text { annum. }\end{array}$ & $\begin{array}{l}\text { Clean } \\
\text { price } £\end{array}$ & $\begin{array}{r}\text { Gross } \\
\text { redempti- } \\
\text { on yield } \\
\% \text { per } \\
\text { annum. }\end{array}$ & $\begin{array}{l}\text { Clean } \\
\text { price } £\end{array}$ & $\begin{array}{r}\text { Gross } \\
\text { redempti- } \\
\text { on yield } \\
\% \text { per } \\
\text { annum. }\end{array}$ & $\begin{array}{l}\text { Clean } \\
\text { price } £\end{array}$ & $\begin{array}{c}\text { Gross } \\
\text { redempti- } \\
\text { on yield } \\
\% \text { per } \\
\text { annum. }\end{array}$ & $\begin{array}{l}\text { Clean } \\
\text { price } £\end{array}$ & $\begin{array}{r}\text { Gross } \\
\text { redempti- } \\
\text { on yield } \\
\% \text { per } \\
\text { annum }\end{array}$ & $\begin{array}{r}\text { Real } \\
\text { clean } \\
\text { price } £\end{array}$ & $\begin{array}{r}\text { Gross } \\
\text { redempti- } \\
\text { on yield } \\
\% \text { per } \\
\text { annum }\end{array}$ \\
\hline
\end{tabular}

Clean prices ${ }^{1}$ and yields ${ }^{2}$

$\begin{array}{cccccc}\text { 2008 Feb } & \text { AJLE } & \text { AJLF } & \text { AJLG } & \text { AJLH } & \text { HRZR } \\ \text { Mar } & 55.15 & 4.526 & 78.72 & 4.446 & 290.75 \\ \text { Apr } & 53.04 & 4.533 & 78.59 & 4.453 & 294.31 \\ \text { May } & 52.58 & 4.755 & 75.53 & 4.634 & 288.69 \\ \text { Jun } & 52.30 & 4.780 & 74.47 & 4.675 & 289.46 \\ & & & & 4.699 & 291.86 \\ \text { Jul } & 52.19 & 4.790 & 74.30 & 4.710 & 290.16 \\ \text { Aug } & 55.02 & 4.544 & 78.41 & 4.463 & 294.48 \\ \text { Sep } & 53.20 & 4.699 & 75.77 & 4.619 & 292.47 \\ \text { Oct } & 52.59 & 4.754 & 74.88 & 4.674 & 286.96 \\ \text { Nov } & 56.81 & 4.401 & 81.01 & 4.320 & 271.50 \\ \text { Dec } & 61.38 & 4.072 & 87.65 & 3.993 & 281.88 \\ \text { 2009 Jan } & 53.79 & 4.648 & 76.62 & 4.568 & 290.65 \\ \text { Feb } & 54.79 & 4.563 & 78.07 & 4.483 & 288.63 \\ \text { Mar } & 56.86 & 4.397 & 81.07 & 4.317 & 290.42 \\ \text { Apr } & 54.38 & 4.597 & 77.48 & 4.517 & 291.16 \\ \text { May } & 52.29 & 4.781 & 74.45 & 4.701 & 292.68 \\ \text { Jun } & 54.44 & 4.592 & 77.56 & 4.512 & 292.91 \\ & & & & & \\ \text { Jul } & 52.87 & 4.729 & 75.29 & 4.648 & 296.29 \\ \text { Aug } & 57.51 & 4.347 & 82.02 & 4.267 & 299.51 \\ \text { Sep } & 57.30 & 4.363 & 81.72 & 4.283 & 300.21 \\ \text { Oct } & 55.77 & 4.483 & 79.49 & 4.403 & 302.16 \\ \text { Nov } & 56.10 & 4.463 & 79.84 & 4.384 & 303.03 \\ \text { Dec } & 54.62 & 4.577 & 77.82 & 4.497 & 304.45 \\ \text { 2010 Jan } & 52.73 & 4.741 & 75.08 & 4.661 & 306.83 \\ & & & & & \end{array}$

$\begin{array}{rr}\text { HSEU } & \text { AJLS } \\ 1.023 & 277.53 \\ 0.843 & 285.22 \\ 1.507 & 275.17 \\ 1.692 & 275.00 \\ 1.564 & 280.37 \\ & \\ 2.000 & 273.99 \\ 1.436 & 286.74 \\ 1.761 & 280.35 \\ 2.657 & 256.61 \\ 4.656 & 245.46 \\ 2.894 & 268.90 \\ & \\ 1.121 & 276.44 \\ 0.818 & 277.33 \\ 0.757 & 280.46 \\ 0.562 & 279.67 \\ 0.297 & 281.39 \\ 0.467 & 280.26 \\ - & 277.96 \\ - & 284.91 \\ - & 287.18 \\ - & 292.00 \\ -1.124 & 293.81 \\ -1.405 & 295.13 \\ -1.709 & 295.32\end{array}$

$\begin{array}{rr}\text { AJLT } & \text { AJOO } \\ 1.267 & 256.12 \\ 0.993 & 258.18 \\ 1.500 & 252.26 \\ 1.624 & 254.01 \\ 1.420 & 262.60 \\ & \\ 1.833 & 256.89 \\ 1.179 & 273.40 \\ 1.525 & 259.07 \\ 2.860 & 253.10 \\ 3.460 & 229.53 \\ 2.012 & 242.78 \\ & \\ 1.406 & 247.12 \\ 1.152 & 240.60 \\ 1.061 & 248.80 \\ 1.080 & 246.41 \\ 0.986 & 251.50 \\ 1.125 & 253.78 \\ & \\ 1.283 & 248.62 \\ 0.881 & 258.59 \\ 0.808 & 257.36 \\ 0.593 & 264.29 \\ 0.521 & 266.89 \\ 0.466 & 267.00 \\ & \\ 0.544 & 261.03\end{array}$

\begin{tabular}{rr} 
AJOP & \multicolumn{1}{r}{ A5FQ } \\
1.086 & 153.80 \\
1.076 & 155.34 \\
1.264 & 152.88 \\
1.275 & 156.61 \\
1.061 & 163.42 \\
& \\
1.275 & 53.07 \\
0.798 & 170.12 \\
1.216 & 157.59 \\
1.991 & 145.22 \\
2.148 & 146.35 \\
1.649 & 155.76 \\
& \\
1.405 & 155.04 \\
1.504 & 140.65 \\
1.287 & 146.70 \\
1.352 & 144.93 \\
1.195 & 149.26 \\
1.166 & 155.76 \\
& \\
1.344 & 153.92 \\
1.028 & 159.19 \\
1.094 & 157.16 \\
0.911 & 163.08 \\
0.850 & 164.79 \\
0.858 & 164.91 \\
1.088 & 157.00
\end{tabular}

$\begin{array}{lr}\text { A5FR } & \text { E7RZ } \\ 0.785 & 125.69 \\ 0.770 & 127.54 \\ 0.856 & 128.93 \\ 0.784 & 135.42 \\ 0.607 & 138.53 \\ & \\ 4.710 & 132.40 \\ 0.444 & 139.91 \\ 0.812 & 127.34 \\ 1.224 & 117.77 \\ 1.169 & 113.98 \\ 0.830 & 125.20 \\ & \\ 0.784 & 124.15 \\ 1.184 & 106.81 \\ 1.008 & 118.68 \\ 1.062 & 118.39 \\ 0.922 & 117.02 \\ 0.743 & 124.51 \\ & \\ 0.811 & 126.48 \\ 0.645 & 131.09 \\ 0.725 & 134.27 \\ 0.565 & 137.76 \\ 0.525 & 136.72 \\ 0.529 & 140.71 \\ & \\ 0.799 & 132.76\end{array}$

Nominal amount outstanding at end of year: $£$ million

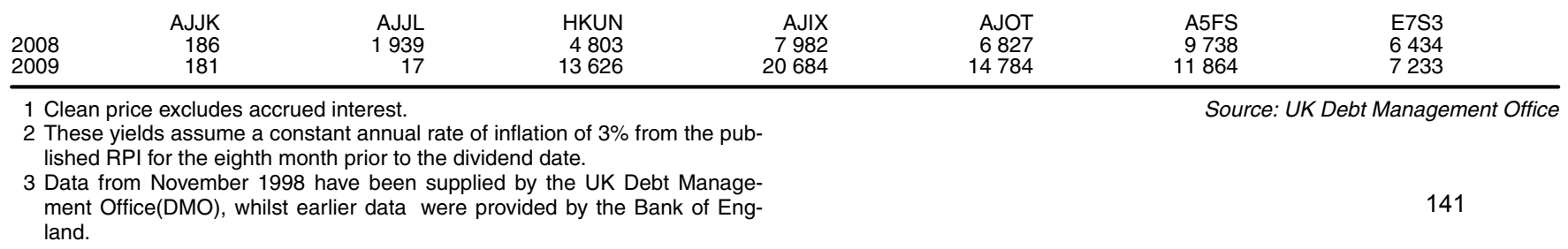




\section{British government securities:yield curve data}

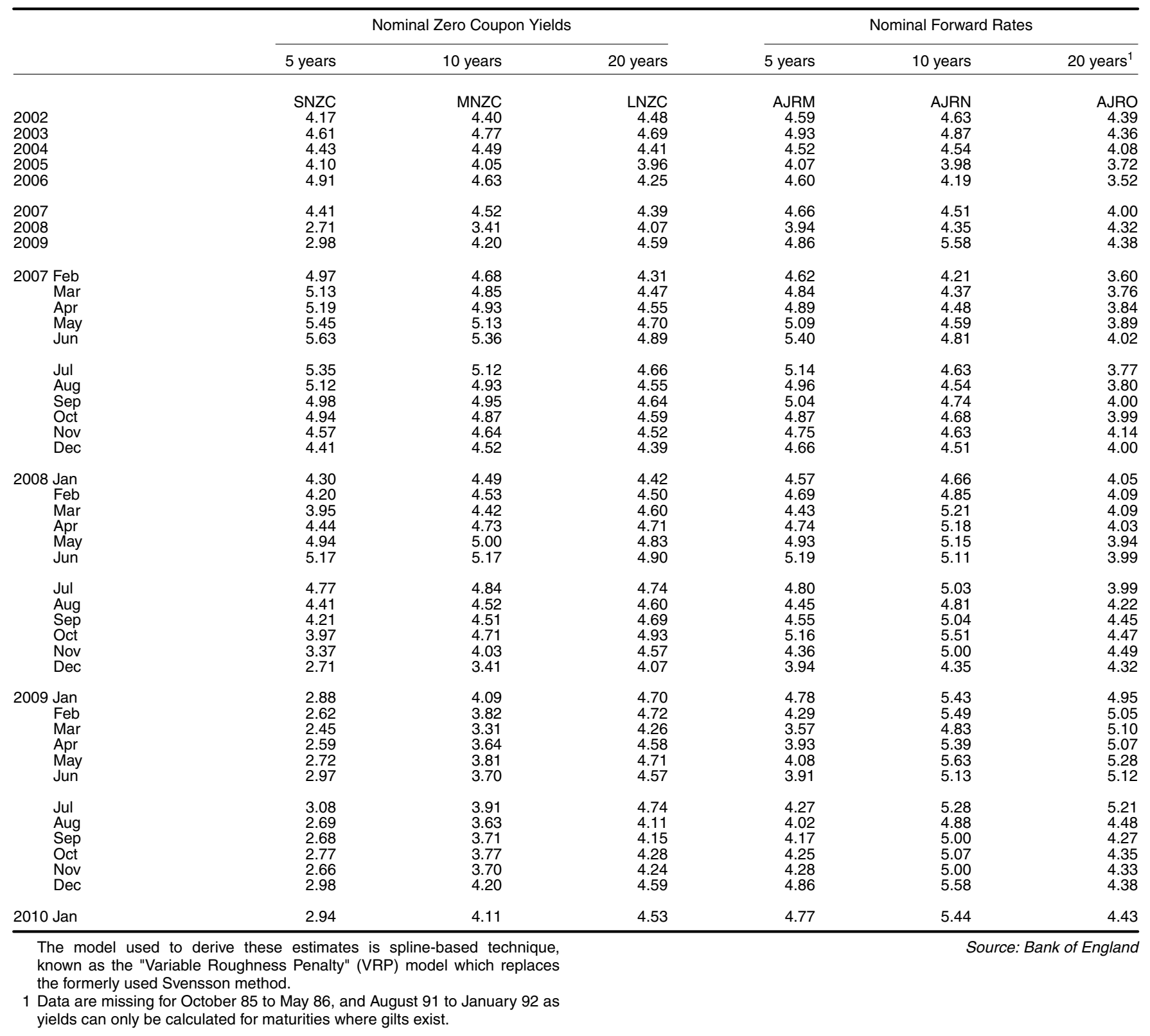




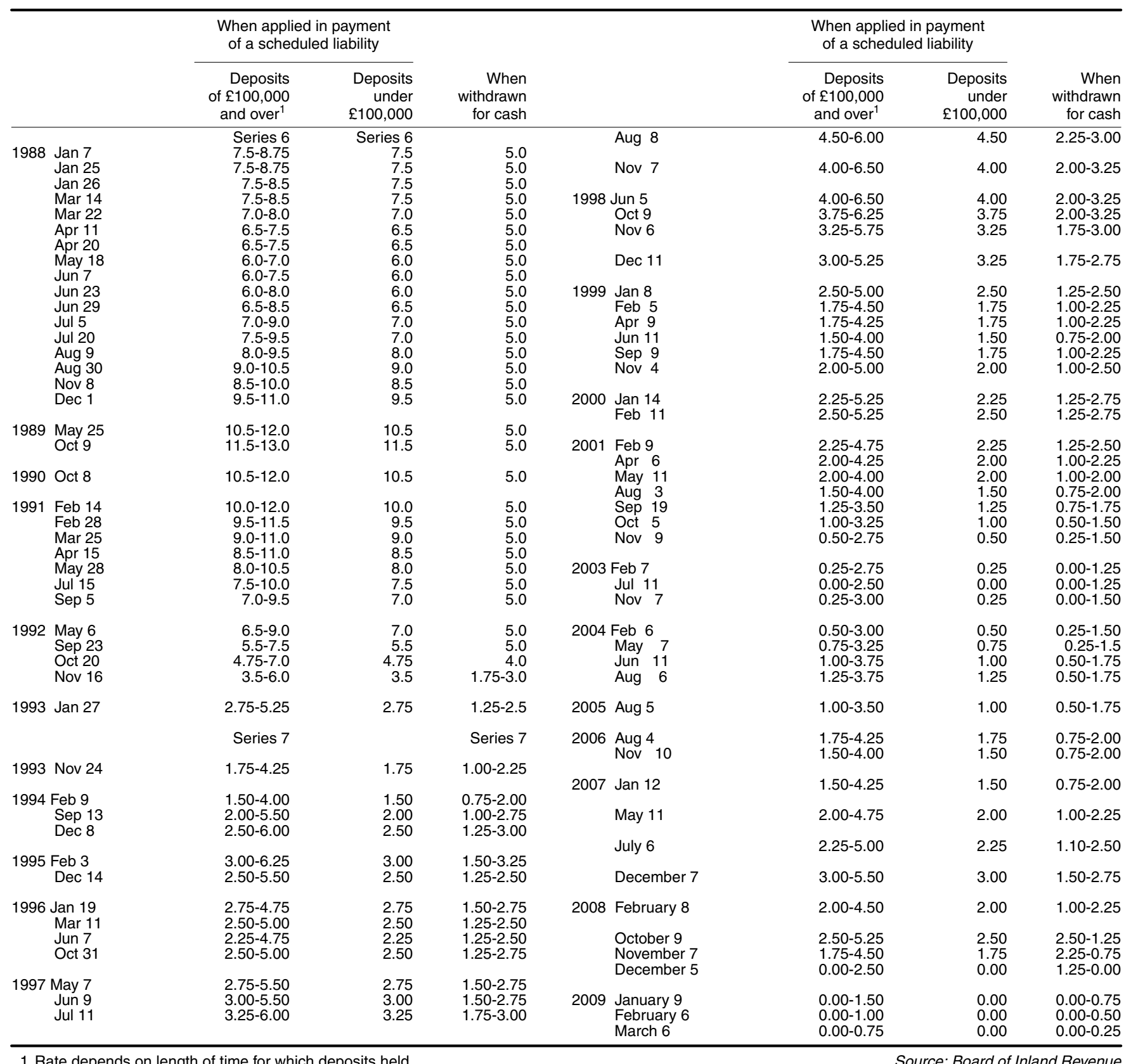




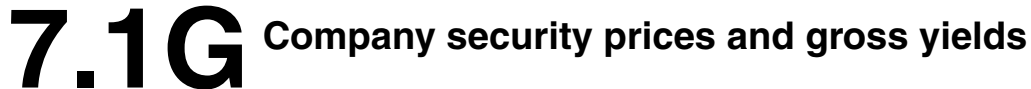

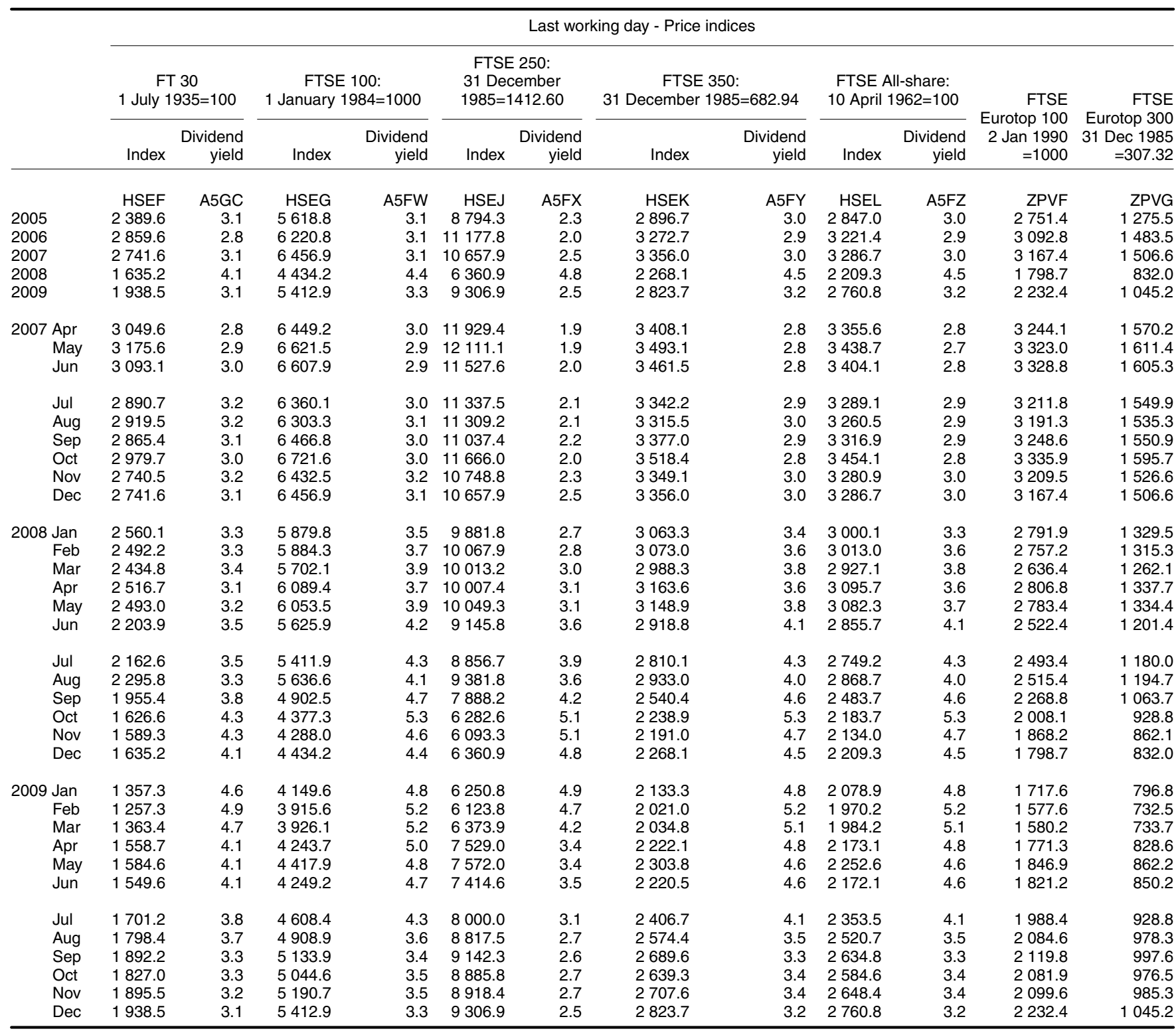




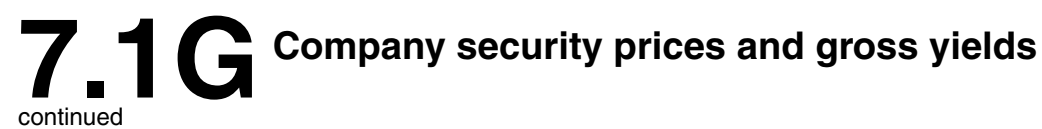

\begin{tabular}{|c|c|c|c|c|c|c|c|c|c|c|}
\hline & \multicolumn{10}{|c|}{ Last working day - Price indices } \\
\hline & \multicolumn{2}{|c|}{ Resources } & \multicolumn{2}{|c|}{ Basic industries } & \multicolumn{2}{|c|}{ Cyclical consumer goods } & \multicolumn{2}{|c|}{ Non-cyclical consumer goods } & \multicolumn{2}{|c|}{ Cyclical services } \\
\hline & Index & $\begin{array}{r}\text { Dividend } \\
\text { yield }\end{array}$ & Index & $\begin{array}{r}\text { Dividend } \\
\text { yield }\end{array}$ & Index & $\begin{array}{r}\text { Dividend } \\
\text { yield }\end{array}$ & Index & $\begin{array}{r}\text { Dividend } \\
\text { yield }\end{array}$ & Index & $\begin{array}{r}\text { Dividend } \\
\text { yield }\end{array}$ \\
\hline & ZPVH & A8SG & ZPVI & A5G3 & ZPVK & A5G5 & ZPVL & A5G6 & ZPVM & A5G7 \\
\hline 2005 & 7672.6 & 2.6 & 3878.7 & 2.5 & 7248.2 & 3.2 & 6641.0 & 2.7 & 3374.7 & 2.6 \\
\hline 2006 & 7559.9 & 3.1 & 4853.6 & 1.6 & 8456.5 & 2.8 & 6323.6 & 2.8 & 3957.0 & 2.2 \\
\hline 2007 & 9043.6 & 2.7 & 7220.8 & 1.2 & 9371.4 & 2.7 & 5761.8 & 3.4 & 3725.1 & 2.7 \\
\hline 2008 & 7543.7 & 4.0 & 3198.5 & 3.8 & 7566.0 & 3.8 & 6022.7 & 4.0 & 2409.0 & 4.4 \\
\hline 2009 & 8636.1 & 4.4 & 6597.5 & 0.8 & 9320.4 & 3.1 & 6381.2 & 4.0 & 3074.2 & 2.8 \\
\hline 2007 Apr & 7514.0 & 3.2 & 5401.9 & 1.8 & 9086.8 & 2.5 & 6711.8 & 2.8 & 4349.5 & 2.1 \\
\hline May & 7812.0 & 3.0 & 6069.9 & 1.3 & 9308.0 & 2.5 & 6300.1 & 3.0 & 4427.0 & 2.0 \\
\hline Jun & 8402.8 & 2.8 & 6288.1 & 1.3 & 9140.6 & 2.5 & 6294.4 & 3.0 & 4172.6 & 2.1 \\
\hline Jul & 8047.0 & 3.0 & 6259.0 & 1.2 & 8746.6 & 2.7 & 6036.6 & 3.2 & 4054.8 & 2.2 \\
\hline Aug & 7908.2 & 3.0 & 6042.4 & 1.4 & 8899.2 & 2.7 & 6065.0 & 3.2 & 4048.5 & 2.2 \\
\hline Oct & 8806.3 & 2.7 & 7294.5 & 1.2 & 9244.1 & 2.7 & 5871.2 & 3.3 & 4157.1 & 2.3 \\
\hline Nov & 8483.4 & 2.8 & 7459.3 & 1.1 & 9203.7 & 2.7 & 5905.9 & 3.3 & 3736.7 & 2.7 \\
\hline Dec & 9043.6 & 2.7 & 7220.8 & 1.2 & 9371.4 & 2.7 & 5761.8 & 3.4 & 3725.1 & 2.7 \\
\hline 2008 Jan & 7872.2 & 3.1 & 6857.7 & 1.2 & 8436.9 & 3.0 & 5403.4 & 3.7 & 3374.7 & 3.0 \\
\hline Feb & 8138.0 & 3.2 & 7751.9 & 1.4 & 8473.7 & 3.1 & 5078.9 & 4.2 & 3232.4 & 3.2 \\
\hline Mar & 7783.1 & 3.4 & 7169.4 & 1.5 & 8599.6 & 3.1 & 4955.2 & 4.3 & 3102.4 & 3.3 \\
\hline Apr & 9123.4 & 3.0 & 8072.5 & 1.3 & 8642.1 & 3.2 & 5217.8 & 4.2 & 3165.1 & 3.4 \\
\hline May & 9301.5 & 3.0 & 8324.4 & 1.3 & 8528.8 & 3.2 & 5229.2 & 4.2 & 3180.3 & 3.5 \\
\hline Jun & 9073.9 & 3.0 & 8278.5 & 1.3 & 7602.0 & 3.7 & 5147.4 & 4.2 & 2795.4 & 4.0 \\
\hline Jul & 7992.3 & 3.6 & 7207.7 & 1.5 & 7554.3 & 3.8 & 5538.1 & 4.0 & 2740.7 & 4.1 \\
\hline Aug & 8348.9 & 3.4 & 7054.0 & 1.7 & 8010.1 & 3.5 & 6117.5 & 3.6 & 2921.3 & 3.8 \\
\hline Sep & 7071.4 & 4.0 & 4661.0 & 2.6 & 7662.4 & 3.6 & 5636.6 & 3.9 & 2620.8 & 4.2 \\
\hline Oct & 7199.3 & 4.2 & 3622.1 & 3.4 & 7127.0 & 3.9 & 5663.1 & 4.2 & 2261.4 & 4.9 \\
\hline Nov & 7390.4 & 4.1 & 3172.3 & 3.8 & 7139.3 & 4.0 & 5319.4 & 4.5 & 2217.3 & 4.9 \\
\hline Dec & 7543.7 & 4.0 & 3198.5 & 3.8 & 7566.0 & 3.8 & 6022.7 & 4.0 & 2409.0 & 4.4 \\
\hline 2009 Jan & 7241.1 & 4.2 & 2947.8 & 4.1 & 7594.9 & 3.7 & 5788.7 & 4.1 & 2356.6 & 4.6 \\
\hline Feb & 6871.3 & 4.9 & 2998.7 & 4.1 & 6999.7 & 4.2 & 5167.8 & 4.6 & 2307.1 & 4.6 \\
\hline May & 7653.0 & 5.0 & 4543.1 & 2.7 & 7241.2 & 3.9 & 5198.6 & 5.0 & 2568.9 & 3.9 \\
\hline Jun & 7076.0 & 5.4 & 4230.7 & 2.5 & 7241.0 & 3.9 & 5337.6 & 4.9 & 2479.0 & 3.8 \\
\hline Jul & 7278.6 & 4.8 & 4921.0 & 2.1 & 7951.1 & 3.7 & 5676.2 & 4.5 & 2668.9 & 3.4 \\
\hline Aug & 7778.1 & 4.5 & 5031.3 & 1.0 & 8151.1 & 3.5 & 5912.4 & 4.3 & 2818.0 & 3.2 \\
\hline Sep & 8126.7 & 4.3 & 5353.7 & 0.9 & 8621.8 & 3.3 & 6002.4 & 4.2 & 2942.2 & 3.0 \\
\hline Oct & 8243.0 & 4.3 & 5378.1 & 0.9 & 8655.7 & 3.3 & 5997.3 & 4.3 & 2896.7 & 3.1 \\
\hline Nov & 8295.7 & 4.6 & 6197.9 & 0.8 & 8692.1 & 3.4 & 6032.1 & 4.2 & 2988.0 & 3.0 \\
\hline Dec & 8636.1 & 4.4 & 6597.5 & 0.8 & 9320.4 & 3.1 & 6381.2 & 4.0 & 3074.2 & 2.8 \\
\hline
\end{tabular}




\section{$7 G$ Company security prices and gross yields

\begin{tabular}{|c|c|c|c|c|c|c|c|c|c|}
\hline & \multicolumn{9}{|c|}{ Last working day - Price indices } \\
\hline & \multicolumn{2}{|c|}{ Non-cyclical services } & \multicolumn{2}{|c|}{ Utilities } & \multicolumn{2}{|c|}{$\begin{array}{l}\text { FTSE industry sector } \\
\text { non-financial }\end{array}$} & \multicolumn{2}{|c|}{ Financials } & \multirow{2}{*}{$\begin{array}{l}\text { Information } \\
\text { technology }\end{array}$} \\
\hline & Index & Dividend yield & Index & Dividend yield & Index & Dividend yield & Index & Dividend yield & \\
\hline & ZPVN & A5G8 & ZPVO & A5G9 & HSER & A5GA & ZPVQ & A5GB & ZPVP \\
\hline 2005 & 2109.2 & 3.0 & 5053.4 & 4.1 & 2784.5 & 2.7 & 6353.2 & 3.5 & 460.5 \\
\hline 2006 & 2497.0 & 4.1 & 6831.4 & 3.0 & 3114.8 & 2.7 & 7388.6 & 3.3 & 462.1 \\
\hline 2007 & 3045.4 & 3.9 & 7300.4 & 3.3 & 3447.2 & 2.6 & 6123.8 & 4.1 & 432.4 \\
\hline 2008 & 2147.6 & 6.1 & 6041.6 & 4.5 & 2544.0 & 4.2 & 3012.4 & 5.6 & 291.9 \\
\hline 2009 & 2228.6 & 5.0 & 6000.6 & 5.3 & 3170.8 & 3.3 & 3769.2 & 2.9 & 513.4 \\
\hline 2007 Apr & 2570.1 & 4.0 & 7133.0 & 3.0 & 3304.4 & 2.6 & 7372.5 & 3.2 & 492.6 \\
\hline May & 2782.2 & 3.8 & 7241.3 & 3.0 & 3414.1 & 2.5 & 7407.3 & 3.3 & 491.8 \\
\hline Jun & 2907.2 & 3.6 & 6888.1 & 3.0 & 3422.3 & 2.5 & 7108.6 & 3.4 & 478.2 \\
\hline Jul & 2639.0 & 4.0 & 6563.2 & 3.2 & 3295.0 & 2.6 & 6929.9 & 3.6 & 487.2 \\
\hline Aug & 2760.2 & 3.8 & 6714.6 & 3.2 & 3294.5 & 2.6 & 6722.9 & 3.7 & 482.0 \\
\hline Oct & 3166.8 & 3.3 & 7157.5 & 3.0 & 3541.4 & 2.5 & 6856.1 & 3.6 & 498.7 \\
\hline Nov & 2998.0 & 4.0 & 7275.5 & 3.3 & 3412.3 & 2.7 & 6263.5 & 4.0 & 427.1 \\
\hline Dec & 3045.4 & 3.9 & 7300.4 & 3.3 & 3447.2 & 2.6 & 6123.8 & 4.1 & 432.4 \\
\hline 2008 Jan & 2839.4 & 4.2 & 6790.5 & 3.6 & 3140.6 & 2.9 & 5621.2 & 4.5 & 398.2 \\
\hline Feb & 2634.0 & 4.5 & 6641.4 & 4.0 & 3167.5 & 3.1 & 5576.6 & 5.0 & 376.8 \\
\hline Mar & 2447.3 & 4.9 & 6488.6 & 4.2 & 3053.8 & 3.2 & 5536.2 & 5.2 & 367.7 \\
\hline Apr & 2544.5 & 4.7 & 6706.2 & 4.0 & 3 277.9 & 3.1 & 5609.6 & 5.1 & 386.3 \\
\hline May & 2611.8 & 5.0 & 6903.8 & 4.1 & 3324.9 & 3.1 & 5277.4 & 5.7 & 408.2 \\
\hline Jun & 2403.8 & 5.4 & 6581.0 & 4.3 & 3143.6 & 3.3 & 4579.0 & 6.7 & 381.2 \\
\hline Jul & 2195.1 & 5.9 & 6626.0 & 4.4 & 2958.1 & 3.6 & 4741.5 & 6.3 & 398.0 \\
\hline Aug & 2265.7 & 5.7 & 6821.6 & 4.1 & 3094.5 & 3.4 & 4909.8 & 5.8 & 428.1 \\
\hline Sep & 2001.3 & 6.5 & 6701.0 & 4.2 & 2652.6 & 4.0 & 4378.5 & 6.5 & 361.2 \\
\hline Oct & 1835.7 & 7.1 & 6174.1 & 4.6 & 2440.5 & 4.4 & 3332.2 & 8.4 & 300.6 \\
\hline Nov & 1991.1 & 6.6 & 5776.3 & 4.7 & 2408.0 & 4.4 & 3145.3 & 5.5 & 284.6 \\
\hline Dec & 2147.6 & 6.1 & 6041.6 & 4.5 & 2544.0 & 4.2 & 3012.4 & 5.6 & 291.9 \\
\hline 2009 Jan & 1969.9 & 6.7 & 5812.6 & 5.1 & 2452.5 & 4.4 & 2558.7 & 6.7 & 304.9 \\
\hline Feb & 1870.5 & 7.0 & 5643.0 & 5.3 & 2325.9 & 4.8 & 2416.4 & 7.0 & 310.3 \\
\hline May & 1768.0 & 6.6 & 5579.0 & 5.6 & 2570.1 & 4.4 & 3142.4 & 5.2 & 408.2 \\
\hline Jun & 1810.3 & 6.4 & 5193.0 & 6.0 & 2487.2 & 4.4 & 2991.1 & 5.0 & 407.6 \\
\hline Jul & 1934.6 & 6.0 & 5109.3 & 6.2 & 2658.3 & 4.0 & 3393.8 & 4.4 & 430.2 \\
\hline Aug & 2081.8 & 5.6 & 5458.7 & 5.8 & 2803.0 & 3.7 & 3819.5 & 3.0 & 460.7 \\
\hline Sep & 2160.6 & 5.4 & 5558.9 & 5.7 & 2932.2 & 3.5 & З 982.1 & 2.9 & 503.8 \\
\hline Oct & 2094.7 & 5.6 & 5366.4 & 5.9 & 2919.8 & 3.5 & 3726.7 & 3.0 & 482.1 \\
\hline Nov & 2149.3 & 5.2 & 5675.2 & 5.7 & 3013.4 & 3.5 & 3730.3 & 2.9 & 489.1 \\
\hline Dec & 2228.6 & 5.0 & 6000.6 & 5.3 & 3170.8 & 3.3 & 3769.2 & 2.9 & 513.4 \\
\hline
\end{tabular}




\section{Short-term sterling money rates (13.8) \\ Last Friday of the period}

Per cent per annum

\begin{tabular}{|c|c|c|c|c|c|c|c|c|c|c|c|c|c|c|c|}
\hline & & \multirow{2}{*}{\multicolumn{2}{|c|}{$\begin{array}{c}\text { Treasury bills }{ }^{1} \\
3 \text { months }\end{array}$}} & \multicolumn{4}{|c|}{ Eligible bills ${ }^{2}$} & \multicolumn{4}{|c|}{ Commercial paper } & \multicolumn{4}{|c|}{ Certificates of deposit } \\
\hline & & & & \multicolumn{2}{|c|}{1 month } & \multicolumn{2}{|c|}{3 month } & \multicolumn{2}{|c|}{1 month } & \multicolumn{2}{|c|}{3 month } & \multicolumn{2}{|c|}{1 month } & \multicolumn{2}{|c|}{3 month } \\
\hline & & $\begin{array}{l}\text { Average } \\
\text { rate of } \\
\text { discount }\end{array}$ & Yield & Bid & Offer & Bid & Offer & Bid & Offer & Bid & Offer & Bid & Offer & Bid & Offer \\
\hline & & AJNB & AJRP & $A J R Q$ & AJRR & AJRS & AJRT & AJRU & AJRV & AJRW & AJRX & AJRZ & AJTJ & HSAL & HSAM \\
\hline 2005 & & 4.43 & 4.48 & .. & .. & .. & .. & 4.57 & 4.60 & 4.56 & 4.59 & 4.59 & 4.63 & 4.57 & 4.61 \\
\hline 2006 & & 5.11 & 5.17 & .. &.. &.. &.. & 5.18 & 5.20 & 5.26 & 5.29 & 5.21 & 5.24 & 5.26 & 5.29 \\
\hline 2007 & & 5.24 & 5.31 & .. &.. & .. &.. & 6.43 & 6.50 & 5.96 & 6.32 & 5.90 & 6.00 & 5.90 & 6.00 \\
\hline 2008 & & 1.24 & 1.25 & .. &.. &.. &.. & 1.63 & 2.19 & 2.03 & 3.15 & 2.00 & 2.25 & 2.65 & 2.90 \\
\hline 2009 & & 0.49 & 0.49 & .. &.. &.. &.. & 0.41 & 0.65 & 0.50 & 0.82 & 0.37 & 0.62 & 0.45 & 0.70 \\
\hline 2007 May & 25 & 5.59 & 5.67 & .. &.. & .. & .. & 5.62 & 5.64 & 5.76 & 5.78 & 5.61 & 5.64 & 5.89 & 5.92 \\
\hline Jun & 29 & 5.77 & 5.79 & .. &.. & .. & .. & 5.81 & 5.84 & 5.93 & 5.96 & 5.81 & 5.84 & 6.06 & 6.09 \\
\hline Aug & 31 & 5.77 & 5.83 & .. &.. & .. &.. & 6.51 & 6.57 & 6.58 & 6.64 & 6.45 & 6.55 & 6.49 & 6.59 \\
\hline Sep & 28 & 5.61 & 5.72 & .. &.. & .. &.. & 6.08 & 6.20 & 6.20 & 6.31 & 6.03 & 6.13 & 6.18 & 6.28 \\
\hline Oct & 26 & 5.57 & 5.65 & .. &.. & .. &.. & 5.92 & 5.98 & 6.16 & 6.22 & 5.94 & 6.01 & 6.15 & 6.25 \\
\hline Nov & 30 & 5.44 & 5.51 & .. &.. & .. &.. & 6.05 & 6.14 & 6.55 & 6.67 & 5.99 & 6.09 & 6.50 & 6.60 \\
\hline Dec & 28 & 5.24 & 5.31 & .. &.. &.. & .. & 6.43 & 6.50 & 5.96 & 6.32 & 5.90 & 6.00 & 5.90 & 6.00 \\
\hline 2008 Jan & 25 & 5.01 & 5.07 & .. &.. & .. &.. & 5.40 & 5.55 & 5.47 & 5.58 & 5.49 & 5.57 & 5.50 & 5.58 \\
\hline Feb & 29 & 4.98 & 5.43 & .. &.. & .. &.. & 5.45 & 5.56 & 5.65 & 5.73 & 5.50 & 5.58 & 5.64 & 5.72 \\
\hline Mar & 28 & 4.77 & 4.83 &.. &.. &.. &.. & 5.64 & 5.80 & 5.78 & 6.03 & 5.70 & 5.78 & 5.94 & 6.02 \\
\hline Apr & 25 & 4.90 & 4.61 & .. &.. &.. &.. & 5.33 & 5.52 & 5.52 & 5.81 & 5.40 & 5.48 & 5.76 & 5.84 \\
\hline May & 30 & 5.04 & 5.06 & .. &.. & .. &.. & 5.34 & 5.49 & 5.70 & 5.87 & 5.38 & 5.46 & 5.79 & 5.87 \\
\hline Jun & 27 & 5.10 & 5.24 & .. &.. &.. &.. & 5.42 & 5.52 & 5.83 & 5.91 & 5.43 & 5.51 & 5.87 & 5.95 \\
\hline Jul & 25 & 5.09 & 5.15 & .. &.. & .. &.. & 5.28 & 5.44 & 5.67 & 5.88 & 5.32 & 5.40 & 5.72 & 5.80 \\
\hline Aug & 29 & 4.94 & 4.99 & .. &.. & .. &.. & 5.21 & 5.40 & 5.53 & 5.74 & 5.30 & 5.38 & 5.69 & 5.77 \\
\hline Sep & 26 & 4.51 & 4.56 & .. & .. & .. & ... & 5.45 & 6.13 & 5.55 & 6.40 & 5.85 & 6.10 & 6.10 & 6.35 \\
\hline Oct & 31 & 3.54 & 3.51 & .. & .. & ... & .. & 5.33 & 5.65 & 5.49 & 5.88 & 5.55 & 5.75 & 5.85 & 6.05 \\
\hline Nov & 28 & 1.68 & 1.69 & .. & .. & ... & ... & 2.78 & 3.27 & 3.06 & 3.87 & 3.05 & 3.30 & 3.85 & 4.10 \\
\hline Dec & 19 & 1.24 & 1.25 & .. &.. &.. &.. & 1.63 & 2.19 & 2.03 & 3.15 & 2.00 & 2.25 & 2.65 & 2.90 \\
\hline Mar & 27 & 0.62 & 0.62 & .. &.. & .. &.. & 0.85 & 1.17 & 1.17 & 1.81 & 0.80 & 1.05 & 1.45 & 1.70 \\
\hline Apr & 24 & 0.57 & 0.57 & .. & .. & .. & ... & 0.65 & 0.95 & 1.13 & 1.52 & 0.60 & 0.85 & 1.20 & 1.45 \\
\hline May & 29 & 0.52 & 0.52 & .. &.. & .. &.. & 0.52 & 0.86 & 0.87 & 1.36 & 0.45 & 0.70 & 1.10 & 1.35 \\
\hline Jun & 26 & 0.49 & 0.49 & .. &.. & .. &.. & 0.48 & 0.80 & 0.85 & 1.23 & 0.40 & 0.65 & 0.95 & 1.20 \\
\hline Jul & 31 & 0.43 & 0.43 & .. &.. & .. &.. & 0.44 & 0.74 & 0.66 & 1.07 & 0.40 & 0.65 & 0.65 & 0.90 \\
\hline Aug & 28 & 0.37 & 0.38 & .. & .. & .. & .. & 0.42 & 0.66 & 0.64 & 1.08 & 0.40 & 0.65 & 0.45 & 0.70 \\
\hline Sep & 25 & 0.39 & 0.39 & .. & .. & .. & .. & 0.46 & 0.74 & 0.42 & 0.72 & 0.35 & 0.60 & 0.35 & 0.60 \\
\hline Oct & 30 & 0.46 & 0.46 & .. &.. &.. &.. & 0.50 & 0.63 & 0.53 & 0.63 & 0.37 & 0.62 & 0.45 & 0.70 \\
\hline Nov & 27 & 0.46 & 0.46 & .. &.. & .. &.. & 0.49 & 0.69 & 0.60 & 0.83 & 0.37 & 0.62 & 0.45 & 0.70 \\
\hline Dec & 18 & 0.49 & 0.49 & .. &.. & .. & .. & 0.41 & 0.65 & 0.50 & 0.82 & 0.37 & 0.62 & 0.45 & 0.70 \\
\hline 2010 Jan & & 0.49 & 0.49 &.. &.. &.. & .. & 0.48 & 0.61 & 0.53 & 0.72 & 0.37 & 0.62 & 0.45 & 0.70 \\
\hline
\end{tabular}


Per cent per annum

\begin{tabular}{|c|c|c|c|c|c|c|c|c|c|c|c|c|c|}
\hline & & \multicolumn{12}{|c|}{ Interbank rates } \\
\hline & & \multicolumn{2}{|c|}{ Overnight } & \multicolumn{2}{|c|}{1 week } & \multicolumn{2}{|c|}{1 month } & \multicolumn{2}{|c|}{3 month } & \multicolumn{2}{|c|}{6 month } & \multicolumn{2}{|c|}{1 year } \\
\hline & & Bid & Offer & Bid & Offer & Bid & Offer & Bid & Offer & Bid & Offer & Bid rate & $\begin{array}{r}\text { Offer } \\
\text { rate }\end{array}$ \\
\hline & & HSAD & HSAE & HSAF & HSAG & $\mathrm{HSAH}$ & HSAI & HSAJ & HSAK & AJTK & AJTL & AJTM & AJTN \\
\hline 2004 & & 4.75 & 4.82 & 4.73 & 4.78 & 4.78 & 4.81 & 4.81 & 4.84 & 4.83 & 4.87 & 4.85 & 4.89 \\
\hline 2005 & & 4.80 & 4.80 & 4.70 & 4.73 & 4.59 & 4.62 & 4.57 & 4.59 & 4.52 & 4.54 & 4.48 & 4.52 \\
\hline 2007 & & 5.80 & 6.00 & 5.75 & 5.85 & 5.90 & 5.95 & 5.95 & 5.95 & 5.85 & 5.87 & 5.65 & 5.67 \\
\hline 2008 & & 1.50 & 2.00 & 1.50 & 2.00 & 2.05 & 2.25 & 2.75 & 2.90 & 2.90 & 3.10 & 3.00 & 3.20 \\
\hline 2009 & & 0.45 & 0.50 & 0.45 & 0.55 & 0.46 & 0.60 & 0.55 & 0.70 & 0.75 & 0.90 & 1.30 & 1.45 \\
\hline $\begin{array}{c}2007 \text { May } \\
\text { Jun }\end{array}$ & $\begin{array}{l}25 \\
29\end{array}$ & $\begin{array}{l}5.57 \\
6.00\end{array}$ & $\begin{array}{l}5.59 \\
6.30\end{array}$ & $\begin{array}{l}5.56 \\
5.90\end{array}$ & $\begin{array}{l}5.58 \\
6.10\end{array}$ & $\begin{array}{l}5.62 \\
5.80\end{array}$ & $\begin{array}{l}5.64 \\
5.85\end{array}$ & $\begin{array}{l}5.76 \\
5.93\end{array}$ & $\begin{array}{l}5.78 \\
5.98\end{array}$ & $\begin{array}{l}5.89 \\
6.05\end{array}$ & $\begin{array}{l}5.92 \\
6.10\end{array}$ & $\begin{array}{l}6.09 \\
6.25\end{array}$ & $\begin{array}{l}6.12 \\
6.29\end{array}$ \\
\hline Jul & 27 & 5.78 & 5.82 & 5.80 & 5.83 & 5.85 & 5.88 & 6.00 & 6.02 & 6.09 & 6.12 & 6.23 & 6.26 \\
\hline Aug & 31 & 6.15 & 6.25 & 6.15 & 6.25 & 6.45 & 6.55 & 6.55 & 6.65 & 6.49 & 6.59 & 6.44 & 6.54 \\
\hline Oct & 26 & 5.82 & 5.87 & 5.80 & 5.85 & 5.97 & 5.98 & 6.17 & 6.25 & 6.14 & 6.20 & 6.01 & 6.11 \\
\hline Nov & 30 & 5.95 & 6.00 & 5.90 & 6.00 & 6.02 & 6.09 & 6.53 & 6.58 & 6.27 & 6.33 & 5.94 & 6.00 \\
\hline Dec & 28 & 5.80 & 6.00 & 5.75 & 5.85 & 5.90 & 5.95 & 5.95 & 5.95 & 5.85 & 5.87 & 5.65 & 5.67 \\
\hline 2008 Jan & 25 & 5.50 & 5.53 & 5.51 & 5.54 & 5.50 & 5.57 & 5.50 & 5.58 & 5.46 & 5.53 & 5.28 & 5.37 \\
\hline Feb & 29 & 5.29 & 5.30 & 5.30 & 5.33 & 5.53 & 5.58 & 5.68 & 5.72 & 5.62 & 5.68 & 5.48 & 5.56 \\
\hline Mar & 28 & 5.45 & 5.50 & 5.45 & 5.50 & 5.72 & 5.78 & 5.95 & 6.02 & 5.93 & 5.98 & 5.75 & 5.84 \\
\hline Apr & 25 & 5.05 & 5.10 & 5.08 & 5.10 & 5.42 & 5.47 & 5.76 & 5.84 & 5.80 & 5.84 & 5.77 & 5.82 \\
\hline May & 30 & 5.05 & 5.10 & 5.07 & 5.10 & 5.38 & 5.45 & 5.80 & 5.87 & 5.91 & 5.99 & 6.10 & 6.12 \\
\hline Jun & 27 & 5.20 & 5.30 & 5.08 & 5.18 & 5.43 & 5.50 & 5.88 & 5.94 & 6.07 & 6.15 & 6.38 & 6.43 \\
\hline Jul & 25 & 5.00 & 5.03 & 5.04 & 5.07 & 5.33 & 5.38 & 5.75 & 5.79 & 5.91 & 5.98 & 6.10 & 6.18 \\
\hline Aug & 29 & 5.00 & 5.02 & 5.03 & 5.07 & 5.31 & 5.36 & 5.70 & 5.75 & 5.84 & 5.89 & 5.95 & 6.00 \\
\hline Sep & 26 & 6.50 & 7.00 & 5.50 & 6.20 & 6.00 & 6.10 & 6.15 & 6.30 & 6.25 & 6.40 & 6.35 & 6.50 \\
\hline Oct & 31 & 4.10 & 4.50 & 4.25 & 4.80 & 5.55 & 5.70 & 5.85 & 6.00 & 5.95 & 6.00 & 5.95 & 6.00 \\
\hline Nov & 28 & 2.50 & 3.00 & 2.60 & 3.10 & 3.05 & 3.25 & 3.85 & 4.10 & 4.00 & 4.20 & 4.00 & 4.25 \\
\hline Dec & 19 & 1.50 & 2.00 & 1.50 & 2.00 & 2.05 & 2.25 & 2.75 & 2.90 & 2.90 & 3.10 & 3.00 & 3.20 \\
\hline 2009 Jan & 30 & 1.25 & 1.60 & 1.30 & 1.75 & 1.50 & 1.70 & 2.00 & 2.25 & 2.15 & 2.40 & 2.30 & 2.50 \\
\hline Feb & 27 & 0.80 & 1.00 & 0.80 & 1.20 & 1.30 & 1.50 & 1.95 & 2.15 & 2.10 & 2.30 & 2.25 & 2.45 \\
\hline May & 29 & 0.40 & 0.55 & 0.45 & 0.65 & 0.55 & 0.70 & 1.15 & 1.30 & 1.40 & 1.50 & 1.75 & 1.80 \\
\hline Jun & 26 & 0.40 & 0.50 & 0.45 & 0.60 & 0.55 & 0.65 & 1.15 & 1.20 & 1.40 & 1.45 & 1.70 & 1.80 \\
\hline Jul & 31 & 0.40 & 0.50 & 0.45 & 0.60 & 0.50 & 0.65 & 0.90 & 0.90 & 1.10 & 1.20 & 1.45 & 1.80 \\
\hline Aug & 28 & 0.40 & 0.50 & 0.45 & 0.60 & 0.45 & 0.65 & 0.70 & 0.70 & 0.90 & 0.95 & 1.20 & 1.25 \\
\hline Sep & 25 & 0.40 & 0.50 & 0.45 & 0.58 & 0.45 & 0.60 & 0.55 & 0.60 & 0.75 & 0.75 & 1.10 & 1.20 \\
\hline Oct & 30 & 0.45 & 0.50 & 0.45 & 0.55 & 0.45 & 0.60 & 0.50 & 0.70 & 0.75 & 0.90 & 1.20 & 1.25 \\
\hline Nov & 27 & 0.45 & 0.50 & 0.45 & 0.55 & 0.45 & 0.62 & 0.50 & 0.70 & 0.75 & 0.90 & 1.20 & 1.30 \\
\hline Dec & 18 & 0.45 & 0.50 & 0.45 & 0.55 & 0.46 & 0.60 & 0.55 & 0.70 & 0.75 & 0.90 & 1.30 & 1.45 \\
\hline 2010 Jan & & 0.45 & 0.50 & 0.45 & 0.55 & 0.45 & 0.60 & 0.50 & 0.70 & 0.75 & 0.94 & 1.25 & 1.35 \\
\hline
\end{tabular}

See table 7.10 for certain average rates.

1 Treasury bills were not tendered in September,October 1989 and August

Source: Bank of England 1992.

2 Discount rates 


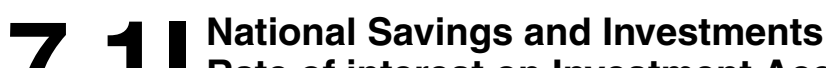 Rate of interest on Investment Account}

Per cent per annum

\begin{tabular}{|c|c|c|c|c|c|c|c|}
\hline Date of change & \multicolumn{3}{|c|}{ New Rate } & Date of change & \multicolumn{3}{|c|}{ New Rate } \\
\hline \multirow{4}{*}{2001 Feb 6} & Under £500 & $£ 500-£ 2,499$ & $£ 2,500-£ 4,999$ & & Under £500 & $£ 500-£ 4,999$ & \\
\hline & 4.25 & 4.35 & 4.45 & & 3.30 & 3.35 & \\
\hline & $£ 5,000-£ 9,999$ & $£ 10,000-24,999$ & $£ 25,000-£ 49,999$ & & $£ 5,000-£ 9,999$ & $£ 10,000-£ 24,999$ & $£ 25,000-£ 49,999$ \\
\hline & 4.55 & 4.75 & 5.05 & & 3.45 & 3.65 & 3.85 \\
\hline \multirow{4}{*}{ May 1} & Under $£ 500$ & $£ 500-£ 2,499$ & $£ 2,500-£ 4,999$ & & Under $£ 500$ & $£ 500-£ 4,999$ & \\
\hline & 4.00 & 4.10 & 4.20 & & 3.55 & 3.60 & \\
\hline & $£ 5,000-£ 9,999$ & $£ 10,000-£ 24,999$ & $£ 25,000-£ 49,999$ & & $£ 5,000-£ 9,999$ & $£ 10,000-£ 24,999$ & $£ 25,000-£ 49,000$ \\
\hline & 4.30 & 4.50 & 4.80 & & 3.70 & 3.90 & 4.10 \\
\hline \multirow[t]{5}{*}{ Jun 7} & & & & May 23 & & & \\
\hline & Under $£ 500$ & $£ 500-£ 2,499$ & $£ 2,500-£ 4,999$ & & Under $£ 500$ & $£ 500-£ 4,999$ & \\
\hline & 3.75 & $\begin{array}{r}2000-2<, 400 \\
3.85\end{array}$ & $\begin{array}{r}2<, 000-24,050 \\
3.95\end{array}$ & & 3.70 & $\begin{array}{r}2000-24,005 \\
3.75\end{array}$ & \\
\hline & $£ 5,000-£ 9,999$ & $£ 10,000-£ 24,999$ & $£ 25,000-£ 49,000$ & & $£ 5,000-£ 9,999$ & $£ 10,000-£ 24,999$ & $£ 25,000-£ 49,000$ \\
\hline & 4.05 & 4.25 & 4.55 & & 3.85 & 4.05 & 4.25 \\
\hline \multirow[t]{4}{*}{ Dec 14} & & & & Jul 25 & & & \\
\hline & 2.60 & 2.70 & & & 3.95 & 4.00 & \\
\hline & $£ 5,000-£ 9,999$ & $£ 10,000-£ 24,999$ & $£ 25,000-£ 49,000$ & & $£ 5,000-£ 9,999$ & $£ 10,000-£ 24,999$ & $£ 25,000-£ 49,000$ \\
\hline & 2.80 & 3.00 & 3.20 & & 4.10 & 4.30 & 4.50 \\
\hline \multirow[t]{5}{*}{$2003 \operatorname{Mar} 3$} & & & & Dec 20 & & & \\
\hline & Under $£ 500$ & $£ 500-£ 4,999$ & & & Under $£ 500$ & $£ 500-£ 4,999$ & \\
\hline & 2.20 & 2.30 & & & 3.70 & 3.75 & \\
\hline & $£ 5,000-£ 9,999$ & $£ 10,000-£ 24,999$ & $£ 25,000-£ 49,000$ & & $£ 5,000-£ 9,999$ & $£ 10,000-£ 24,999$ & $£ 25,000-£ 49,999$ \\
\hline & 2.40 & 2.60 & 2.80 & & 3.85 & 4.05 & 4.25 \\
\hline \multirow[t]{5}{*}{ Aug 3} & & & & 2008 Feb 22 & & & \\
\hline & Under £500 & $£ 500-£ 4,999$ & & & Under $£ 500$ & $£ 500-£ 4,999$ & \\
\hline & 2.00 & 2.05 & & & 3.45 & 3.50 & \\
\hline & $£ 5,000-£ 9,999$ & $£ 10,000-£ 24,999$ & $£ 25,000-£ 49,999$ & & $£ 5,000-£ 9,999$ & $£ 10,000-£ 24,999$ & $£ 25,000-£ 49,999$ \\
\hline & 2.15 & 2.35 & 2.55 & & 3.60 & 3.80 & 4.00 \\
\hline $\operatorname{Dec} 4$ & & & & Apr 23 & & & \\
\hline & Under £500 & $£ 500-£ 4,999$ & & & Under £500 & $£ 500-£ 4,999$ & \\
\hline & 2.25 & 2.30 & & & 3.20 & 3.25 & \\
\hline & $£ 5,000-£ 9,999$ & $£ 10,000-£ 24,999$ & $£ 25,000-£ 49,999$ & & $£ 5,000-£ 9,999$ & $£ 10,000-£ 24,999$ & $£ 25,000-£ 49,999$ \\
\hline & 2.40 & 2.60 & 2.80 & & 3.35 & 3.55 & 3.75 \\
\hline 2004 Mar 4 & & & & Oct 7 & & & \\
\hline & 2.65 & 2.85 & 3.05 & & 3.15 & 3.35 & 3.55 \\
\hline Jun 1 & & & & Oct 22 & & & \\
\hline & Under $£ 500$ & $£ 500-£ 4,999$ & & & Under $£ 500$ & $£ 500-£ 4,999$ & \\
\hline & 2.75 & 2.80 & & & 2.50 & 2.55 & \\
\hline & $£ 5,000-£ 9,999$ & $£ 10,000-£ 24,999$ & $£ 25,000-£ 49,999$ & & $£ 5,000-£ 9,999$ & $£ 10,000-£ 24,999$ & $£ 25,000-£ 49,999$ \\
\hline & 2.90 & 3.10 & 3.30 & & 2.65 & 2.85 & 3.05 \\
\hline Jul 4 & & & & Nov 19 & & & \\
\hline & Under £500 & $£ 500-£ 4,999$ & & & Under £500 & $£ 500-£ 4,999$ & \\
\hline & 3.00 & 3.05 & & & 1.00 & 1.05 & \\
\hline & $£ 5,000-£ 9,999$ & $£ 10,000-£ 24,999$ & $£ 25,000-£ 49,999$ & & $£ 5,000-£ 9,999$ & $£ 10,000-£ 24,999$ & $£ 25,000-£ 49,999$ \\
\hline & $\begin{array}{r}20,000-20,000 \\
3.15\end{array}$ & 3.35 & 3.55 & & 1.15 & 1.35 & 1.55 \\
\hline Sep 1 & & & & 2009 Jan 21 & & & \\
\hline & Under $£ 500$ & $£ 500-£ 4,999$ & & & Under $£ 500$ & $£ 500-£ 4,999$ & \\
\hline & 3.25 & 3.30 & & & 0.35 & 0.35 & \\
\hline & $£ 5,000-£ 9,999$ & $£ 10,000-£ 24,999$ & $£ 25,000-£ 49,999$ & & $£ 5,000-£ 9,999$ & $£ 10,000-£ 24,999$ & $£ 25,000-£ 49,999$ \\
\hline & 3.40 & 3.60 & 3.80 & & 0.35 & 0.35 & 0.55 \\
\hline 2005 Sep 1 & & & & Feb 19 & & & \\
\hline & Under £500 & $£ 500-£ 4,999$ & & & Under £500 & $£ 500-£ 4,999$ & \\
\hline & 2.95 & 3.00 & & & 0.30 & 0.30 & \\
\hline & $£ 5,000-£ 9,999$ & $£ 10,000-£ 24,999$ & $£ 25,000-£ 49,999$ & & $£ 5,000-£ 9,999$ & $£ 10,000-£ 24,999$ & $£ 25,000-£ 49,999$ \\
\hline & 3.10 & 3.30 & 3.50 & & 0.30 & 0.40 & 0.40 \\
\hline 2006 Jun 1 & & & & Mar 18 & & & \\
\hline & Under $£ 500$ & $£ 500-£ 4,999$ & & & Under $£ 500$ & $£ 500-£ 4,999$ & \\
\hline & 2.90 & 2.95 & & & 0.20 & 0.20 & \\
\hline & $£ 5,000-£ 9,999$ & $£ 10,000-£ 24,999$ & $£ 25,000-£ 49,999$ & & $£ 5,000-£ 9,999$ & $£ 10,000-£ 24,999$ & $£ 25,000-£ 49,999$ \\
\hline & 3.05 & 3.25 & 3.45 & & 0.20 & 0.20 & 0.30 \\
\hline Aug 17 & & & & & & & \\
\hline & Under $£ 500$ & $£ 500-£ 4,999$ & & & & & \\
\hline & 3.15 & 3.20 & & & & & \\
\hline & $£ 5,000-£ 9,999$ & $£ 10,000-£ 24,999$ & $£ 25,000-£ 49,999$ & & & & \\
\hline & 3.30 & 3.50 & 3.70 & & & & \\
\hline
\end{tabular}




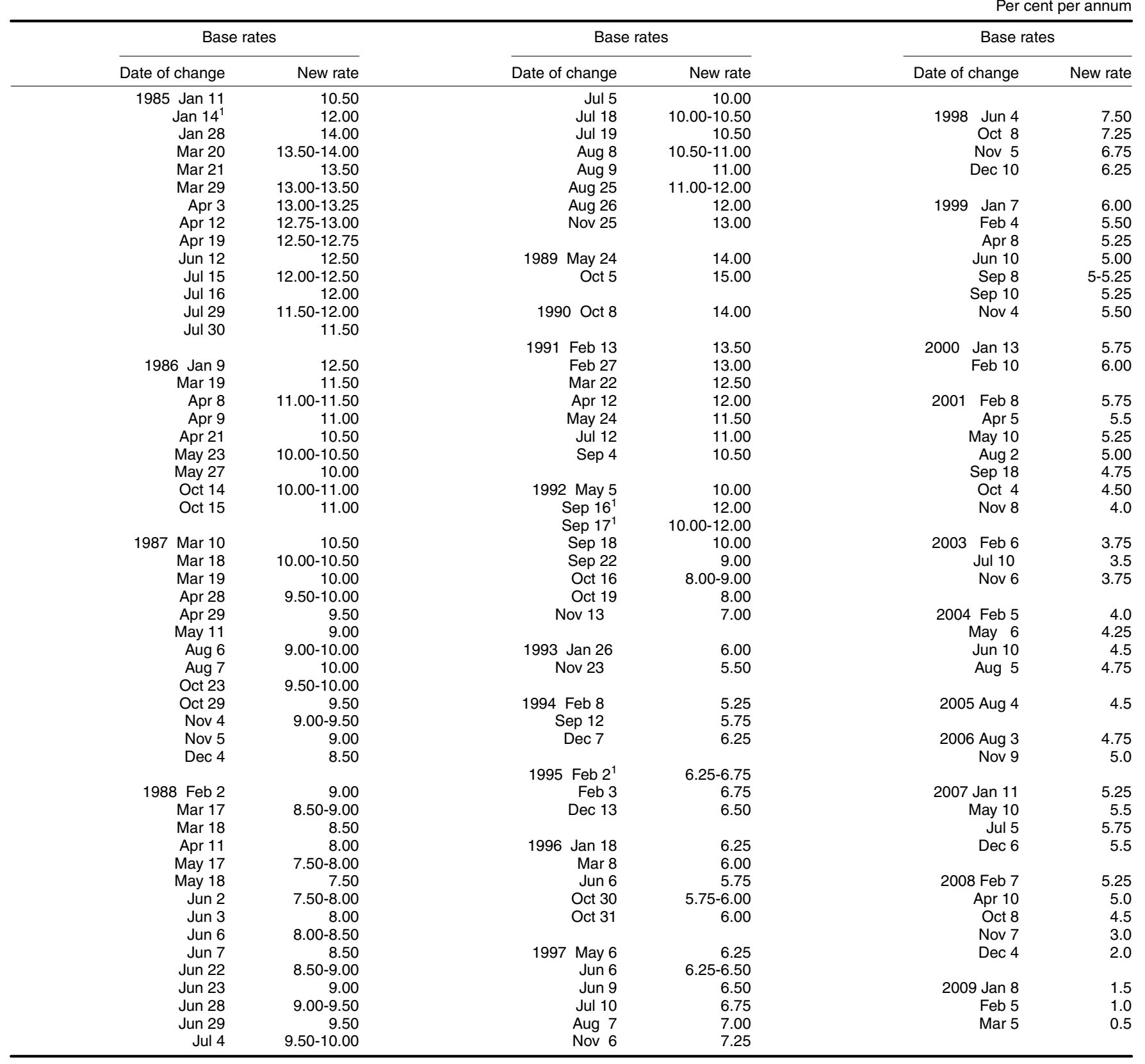




\begin{tabular}{|c|c|c|c|c|c|}
\hline Date of change & New rate & Date of change & New rate & Date of change & New rate \\
\hline 1982 Jan 1 & 15.5 & & & Mar 1 & 7.0 \\
\hline Mar 1 & 15.0 & 1987 Jan 1 & 11.5 & Apr 1 & 6.5 \\
\hline Apr 1 & 14.5 & Mar 1 & 11.0 & Jul 1 & 6.0 \\
\hline May 1 & 14.0 & Apr 1 & 10.5 & & \\
\hline Jul 1 & 13.5 & May 1 & 10.0 & 1994 Jan 1 & 5.5 \\
\hline Aug 1 & 13.0 & Jun 1 & 9.5 & Oct 1 & 6.0 \\
\hline Sep 1 & 12.0 & Jul 1 & 9.0 & $\operatorname{Dec} 1$ & 6.5 \\
\hline Oct 1 & 11.5 & Aug 1 & 9.5 & & \\
\hline Nov 1 & 10.5 & Sep 1 & 10.0 & 1995 Feb 1 & 7.0 \\
\hline \multirow[t]{2}{*}{$\operatorname{Dec} 1$} & 10.0 & Oct 1 & 10.5 & & \\
\hline & & Dec 1 & 9.5 & 1996 Feb 1 & 6.5 \\
\hline 1983 Jan 1 & 10.5 & & & July 1 & 6.0 \\
\hline Feb 1 & 11.0 & 1988 Jan 1 & 9.0 & Dec 1 & 6.5 \\
\hline Mar 1 & 11.5 & Mar 1 & 9.5 & & \\
\hline May 1 & 11.0 & May 1 & 9.0 & 1997 Jun 1 & 7.0 \\
\hline Jun 1 & 10.5 & Jun 1 & 8.5 & Sep 1 & 7.5 \\
\hline Jul 1 & 10.0 & Aug 1 & 10.0 & & \\
\hline \multirow[t]{2}{*}{ Dec 1} & 9.5 & Sep 1 & 11.0 & 1998 Jan 2 & 8.0 \\
\hline & & Oct 1 & 12.0 & Nov 2 & 7.5 \\
\hline Jun 1 & 9.5 & & & 1999 Jan 4 & 7.0 \\
\hline Aug 1 & 10.5 & 1989 Jan 1 & 13.0 & Feb 1 & 6.5 \\
\hline Sep 1 & 11.5 & Feb 1 & 13.5 & Mar 1 & 6.0 \\
\hline Oct 1 & 11.0 & Jul 1 & 14.0 & Apr 1 & 5.5 \\
\hline \multirow[t]{2}{*}{ Dec 1} & 10.5 & Aug 1 & 14.5 & Nov 1 & 6.0 \\
\hline & & Sep 1 & 14.0 & & \\
\hline 1985 Jan 1 & 10.0 & Nov 1 & 15.0 & 2000 Feb 1 & 6.5 \\
\hline Feb 1 & 10.5 & Dec 1 & 15.5 & & \\
\hline Mar 1 & 12.5 & & & 2001 Feb 1 & 6.0 \\
\hline Apr 1 & 14.0 & 1990 Aug 1 & 15.0 & May 1 & 5.5 \\
\hline May 1 & 13.5 & Dec 1 & 14.0 & Oct 1 & 5.0 \\
\hline Jun 1 & 13.0 & & & Dec 1 & 4.5 \\
\hline Aug 1 & 12.5 & 1991 Apr 1 & 13.0 & & \\
\hline \multirow[t]{2}{*}{ Sep 1} & 12.0 & May 1 & 12.5 & 2002 Oct 1 & 4.0 \\
\hline & & Jun 1 & 12.0 & & \\
\hline 1986 Jan 1 & 12.0 & Jul 1 & 11.5 & 2003 Sep 1 & 3.5 \\
\hline Feb 1 & 12.5 & Sep 1 & 11.0 & & \\
\hline Mar 1 & 13.0 & Nov 1 & 10.5 & & \\
\hline Apr 1 & 12.5 & Dec 1 & 11.0 & 2004 Jan 1 & 4.0 \\
\hline May 1 & 11.5 & & & Feb 1 & 4.5 \\
\hline Nov 1 & 11.0 & & & & \\
\hline $\operatorname{Dec} 1$ & 11.5 & 1993 Jan 1 & 7.5 & & \\
\hline
\end{tabular}

On 2nd January 1992 the Finance Houses Association (FHA) merged with the Equipment Leasing Association to form the Finance \& Leasing Associa-

Source: Finance \& Leasing Association tion (FLA).

\begin{tabular}{|c|c|c|c|c|c|}
\hline Date of change & New rate & Date of change & New rate & Date of change & New rate \\
\hline 2006 Nov 1 & 5.5 & & & Mar 1 & 2.5 \\
\hline & & 2008 Mar 1 & 6.0 & Apr 1 & 2.0 \\
\hline 2007 Apr 1 & 6.0 & Nov 1 & 6.5 & Jun 1 & 1.5 \\
\hline Sep 1 & 6.5 & Dec 1 & 5.5 & Sep 1 & 1.0 \\
\hline Oct 1 & 7.0 & 2009 Jan 1 & 4.0 & & \\
\hline Nov 1 & 6.5 & Feb 1 & 3.0 & & \\
\hline
\end{tabular}

On 2nd January 1992 the Finance Houses Association (FHA) merged with the Equipment Leasing Association to form the Finance \& Leasing Associa-

Source: Finance \& Leasing Association tion (FLA). 


\begin{tabular}{|c|c|c|c|c|c|c|c|}
\hline & \multicolumn{7}{|c|}{ End of month observation: Secured lending mortgage rates banks \& building societies } \\
\hline & \multicolumn{4}{|c|}{ Fixed } & \multicolumn{3}{|c|}{ Discounted } \\
\hline & 2 Year (75\% LTV) & 3 Year (75\% LTV) & 5 Year $(75 \%$ LTV $)$ & 10 Year $(75 \%$ LTV) & 2 Year $(75 \%$ LTV) & BTR & SVR \\
\hline & BV34 & BV37 & BV42 & BV45 & BV48 & BV24 & AJVT \\
\hline $2007 \mathrm{Dec}$ & 6.06 & 6.22 & 5.97 & 5.93 & 5.75 & 6.20 & 7.68 \\
\hline 2008 Jan & 5.97 & 6.02 & 5.91 & 5.96 & 5.93 & 6.24 & 7.51 \\
\hline Mar & 5.80 & 5.69 & 5.70 & 5.77 & 5.90 & 6.04 & 7.24 \\
\hline Apr & 6.06 & 5.67 & 5.85 & 5.77 & 6.13 & 5.99 & 7.23 \\
\hline May & 6.26 & 6.13 & 6.11 & 6.18 & 6.20 & 6.17 & 6.95 \\
\hline Jun & 6.60 & 6.39 & 6.40 & 6.46 & 6.04 & 6.31 & 6.92 \\
\hline Jul & 6.35 & 6.39 & 6.37 & 6.44 & 5.97 & 6.26 & 6.92 \\
\hline Aug & 6.08 & 6.06 & 6.09 & 6.24 & 5.96 & 6.20 & 6.93 \\
\hline Sep & 5.96 & 5.86 & 5.84 & 6.04 & 5.95 & 6.12 & 6.95 \\
\hline Oct & 5.82 & 5.94 & 5.88 & 6.20 & 5.98 & 7.04 & 6.91 \\
\hline Nov & 5.10 & 5.46 & 5.47 & 5.85 & 5.08 & 5.78 & 6.34 \\
\hline 2009 Jan & 4.35 & 4.75 & 4.94 & 5.47 & 4.08 & 4.51 & 4.73 \\
\hline Feb & 4.35 & 4.56 & 4.97 & 5.55 & 4.07 & 4.30 & 4.38 \\
\hline Mar & 3.98 & 4.41 & 4.95 & 5.64 & 3.63 & 4.01 & 4.06 \\
\hline Apr & 4.02 & 4.30 & 4.87 & 5.63 & 3.59 & 3.85 & 3.82 \\
\hline May & 3.98 & 4.29 & 4.93 & 5.64 & 3.54 & 3.99 & 3.83 \\
\hline Jun & 4.45 & 4.86 & 5.54 & 6.26 & 3.45 & 3.81 & 3.95 \\
\hline Jul & 4.42 & 4.67 & 5.68 & 6.27 & 3.40 & 3.84 & 4.11 \\
\hline Aug & 4.43 & 4.80 & 5.72 & 6.28 & 3.24 & 3.85 & 3.93 \\
\hline Sep & 4.47 & 4.82 & 5.69 & .. & 3.24 & 3.90 & 3.91 \\
\hline Oct & 4.32 & 4.82 & 5.67 &.. & 3.30 & 3.86 & 3.91 \\
\hline Nov & 4.10 & 4.88 & 5.71 &.. & 3.30 & 3.89 & 3.98 \\
\hline Dec & 4.05 & 4.84 & 5.67 & .. & 3.31 & 3.92 & 3.97 \\
\hline
\end{tabular}

Source: Bank of England

End of month observation:Unsecured lending rates

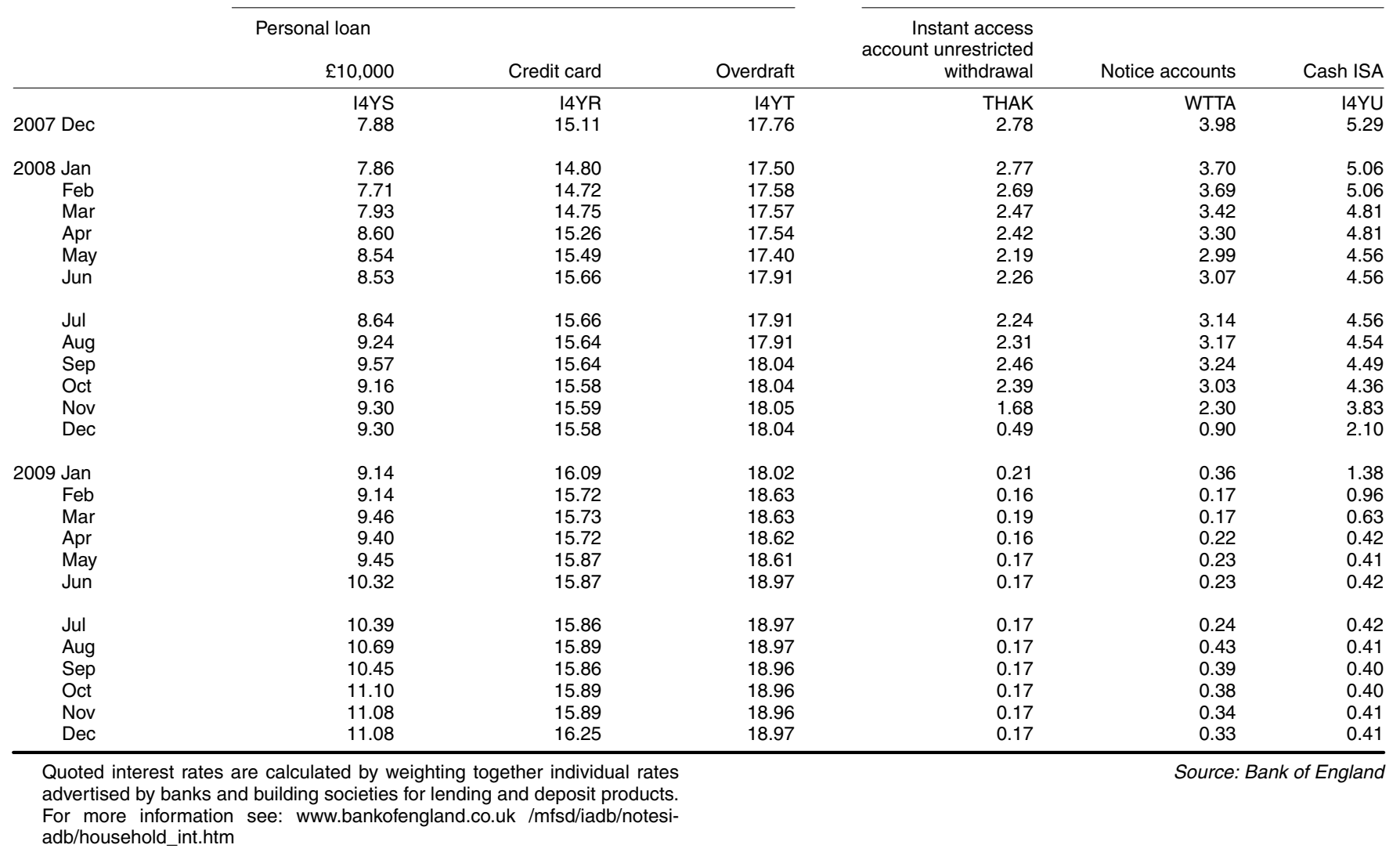


Over 1 1/2 Over 4 1/2 Over 9 1/2 Over 14 1/2 Over 19 1/2 Over 24 1/2 Over 29 1/2 Over 34 1/2 Over 39 1/2 Over 44 1/2 Over 49 1/2 years but years but years but years but years but years but years but years but years but years but years but not over 2 not over 5 not over 10 not over 15 not over 20 not over 25 not over 30 not over 35 not over 40 not over 45 not over 50

Repayable by equal half-yearly instalments (Annuity)

\begin{tabular}{|c|c|c|c|c|}
\hline September 1 & 0.99 & 1.87 & 2.89 & 3.5 \\
\hline September 8 & 0.97 & 1.9 & 2.96 & 3.58 \\
\hline September 15 & 0.98 & 1.9 & 2.95 & 3.56 \\
\hline September 22 & 0.97 & 1.92 & 3.04 & 3.7 \\
\hline September 29 & 0.92 & 1.81 & 2.91 & 3.59 \\
\hline October 6 & 0.90 & 1.74 & 2.74 & 3.36 \\
\hline October 13 & 0.92 & 1.72 & 2.71 & 3.34 \\
\hline October 20 & 1.04 & 1.9 & 2.94 & 3.58 \\
\hline October 27 & 1.07 & 1.97 & 3.05 & 3.68 \\
\hline November 3 & 1.09 & 1.99 & 3.05 & 3.66 \\
\hline November 10 & 0.98 & 1.96 & 3.15 & 3.83 \\
\hline November 17 & 1.03 & 1.92 & 3.06 & 3.75 \\
\hline November 24 & 0.96 & 1.85 & 2.99 & 3.67 \\
\hline December 1 & 0.93 & 1.8 & 2.89 & 3.54 \\
\hline December 8 & 0.94 & 1.81 & 2.96 & 3.69 \\
\hline December 15 & 0.97 & 1.86 & 3.06 & 3.82 \\
\hline December 22 & 0.97 & 1.87 & 3.08 & 3.86 \\
\hline January 5 & 1.06 & 2.01 & 3.23 & 3.97 \\
\hline January 12 & 1.0 & 1.97 & 3.24 & 4.0 \\
\hline January 19 & 1.03 & 1.98 & 3.22 & 3.96 \\
\hline January 26 & 1.04 & 1.98 & 3.2 & 3.94 \\
\hline
\end{tabular}

$\begin{array}{rrr}3.84 & 3.99 & 4.07 \\ 3.93 & 4.1 & 4.18 \\ 3.91 & 4.07 & 4.14 \\ 4.03 & 4.16 & 4.2 \\ 3.95 & 4.09 & 4.15 \\ & & \\ 3.73 & 3.93 & 4.02 \\ 3.72 & 3.91 & 4.00 \\ 3.94 & 4.12 & 4.21 \\ 4.04 & 4.22 & 4.29 \\ & & \\ 4.02 & 4.2 & 4.28 \\ 4.2 & 4.37 & 4.44 \\ 4.13 & 4.31 & 4.38 \\ 4.04 & 4.21 & 4.28 \\ & & \\ 3.91 & 4.11 & 4.21 \\ 4.09 & 4.29 & 4.36 \\ 4.24 & 4.42 & 4.49 \\ 4.26 & 4.43 & 4.48 \\ & & \\ 4.34 & 4.5 & 4.54 \\ 4.37 & 4.51 & 4.56 \\ 4.32 & 4.47 & 4.51 \\ 4.31 & 4.47 & 4.53\end{array}$

4.13
4.23
4.17
4.23
4.18

4.07
4.06
4.26
4.32

4.31
4.46
4.4
4.29

4.24
4.38
4.5
4.48
4.55
4.56
4.52
4.54

$\begin{array}{rrr}4.19 & 4.24 & 4.29 \\ 4.26 & 4.28 & 4.32 \\ 4.2 & 4.21 & 4.25 \\ 4.26 & 4.28 & 4.32 \\ 4.22 & 4.24 & 4.28 \\ & & \\ 4.1 & 4.12 & 4.16 \\ 4.1 & 4.13 & 4.18 \\ 4.29 & 4.3 & 4.34 \\ 4.32 & 4.32 & 4.33 \\ & & \\ 4.32 & 4.31 & 4.33 \\ 4.46 & 4.44 & 4.45 \\ 4.4 & 4.39 & 4.4 \\ 4.28 & 4.27 & 4.27 \\ & & \\ 4.24 & 4.22 & 4.23 \\ 4.38 & 4.37 & 4.37 \\ 4.49 & 4.47 & 4.47 \\ 4.46 & 4.42 & 4.42 \\ & & \\ 4.53 & 4.5 & 4.49 \\ 4.56 & 4.54 & 4.55 \\ 4.51 & 4.5 & 4.5 \\ 4.53 & 4.51 & 4.52 \\ & & \end{array}$

Repayable by equal half-yearly instalments of principal and interest on the balance (EIP)

September 1

September 8

September 15

September 22

September 29

$\begin{array}{ll}0.99 & 1.85\end{array}$

0.97

0.98

0.97
0.91

October 6

October 13

October 20

October 27

0.90

0.91

1.03
1.07

1.08

November 3

November 10

November 17

November 24

0.98

0.98
1.03

0.96

0.93

December

December 8

December 15

0.94

0.97

0.97

1.06

January 5

January 12

January 19

January 26

1.0

1.03

1.04

Principal repayable at maturity

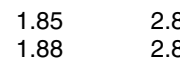

1.88

1.9

1.79

1.72

1.7

1.88
1.95

\subsection{7}

1.94

1.9
1.83

1.78

1.79

1.84
1.85

1.99

1.95
1.96

1.96
2.83
2.89

2.88

2.96

2.84

2.67

2.65

2.87
2.97

2.98

3.07

2.98

2.91

2.82

2.88

2.97

2.99

3.14

3.14

3.13
3.11
3.4

3.47
3.46

3.59

3.47

3.25

3.23

3.47

3.57

3.56

3.71

3.63

3.55

3.43

3.57
3.69

3.72

3.83

3.86

3.83
3.8
3.73

3.73
3.82
3.8

3.93

3.84

3.62

3.6

3.83

3.92

3.9
4.07

4.07
4.0

3.92

3.79

3.96

4.1
4.13

4.22

4.25

4.2
4.18
3.92

3.99

4.1
4.02

3.83

3.82

4.03
4.12

4.1
4.27

4.27

4.21
4.12

4.01

4.18

4.32

4.41

4.41

4.44
4.39

4.38
4.01

4.12
4.09

4.17

4.1

3.95

3.93

4.14

4.22

4.38

4.32

4.23

4.13

4.3

4.43
4.44

4.51

4.52

4.47
4.48
4.06

4.18

4.2

4.14

4.01

4.00

4.2
4.28

4.28

4.43

4.37
4.27

4.2

4.2
4.35

4.48
4.47

4.54

4.54
4.55

4.5

4.52
4.11

4.21

4.

4.22
4.17

4.05

4.04

4.24
4.31

4.3

4.46

4.4
4.29

4.23

4.37

4.5
4.48

4.55

4.56

4.52

4.54
4.15

4.24

4.18

4.24
4.19

4.08

4.07

4.26

4.32

4.32
4.46

4.4
4.29

4.24

4.38

4.5
4.47

4.54

4.56

4.52
4.54
4.19

4.26

4.2
4.26

4.22

4.1

4.1

4.28
4.32

4.32

4.46

4.4
4.28

4.24

4.38

4.49

4.46

4.53

4.56

4.51
4.53

September 1

1.45
1.46

September 15

September 22

September 29

$2.76 \quad 3.71$

4.0

4.1

4.19

4.24

4.29

4.31

$4.32 \quad 4.35$

4.32

4.27

4.34
4.3

4.3

4.35

4.27

4.33

4.16

4.12

4.14

4.18

4.33

4.18

4.22

4.35
4.33

4.19

4.23

4.36

4.36
4.34

4.32

4.31

4.44

4.39

4.44

4.39

4.33

4.45

4.34
4.44

4.39
4.25

4.22

4.22

4.22
4.36

4.47

4.37

4.46

$4.22 \quad 4.21$

4.22
4.37 
Per cent per annum

\begin{tabular}{|c|c|c|c|c|c|c|c|c|c|c|}
\hline & \multicolumn{5}{|c|}{12 Selected retail banks - gross interest } & \multirow{3}{*}{$\begin{array}{r}3 \text { month } \\
\text { Sterling } \\
\text { Interbank }\end{array}$} & \multicolumn{4}{|c|}{ British government securities } \\
\hline & \multirow[b]{2}{*}{$\begin{array}{r}\text { Base } \\
\text { rate }\end{array}$} & \multicolumn{2}{|c|}{ Instant access accounts } & \multicolumn{2}{|c|}{90 day accounts } & & \multicolumn{3}{|c|}{ Nominal zero coupon yields ${ }^{3}$} & \multirow[b]{2}{*}{$\begin{array}{r}3.5 \% \text { War Loan } \\
\text { Flat yield }\end{array}$} \\
\hline & & $\begin{array}{r}\text { low } \\
\text { balance }\end{array}$ & $\begin{array}{l}\text { medium } \\
\text { balance }\end{array}$ & $\begin{array}{l}\text { medium } \\
\text { balance }\end{array}$ & $\begin{array}{r}\text { high } \\
\text { balance }\end{array}$ & & $\begin{array}{r}\text { Short dated } \\
5 \text { years }\end{array}$ & $\begin{array}{r}\text { Medium dated } \\
10 \text { years }\end{array}$ & $\begin{array}{l}\text { Long dated } \\
20 \text { years }\end{array}$ & \\
\hline & $\mathrm{AMIH}$ & AJOU & AJNU & AJOV & AJTQ & AMIJ & AJTS & AJTT & AJTU & AMIL \\
\hline 2005 & 4.65 & .. & .. & .. & .. & 4.69 & 4.33 & 4.37 & 4.33 & 4.38 \\
\hline 2007 & 5.51 & .. & .. & .. & .. & 5.96 & 5.11 & 4.92 & 4.56 & 4.54 \\
\hline 2008 & 4.68 & .. & .. & .. & .. & 5.50 & 4.28 & 4.59 & 4.66 & 4.50 \\
\hline 2009 & 0.64 & .. & .. & .. & .. & 1.19 & 2.76 & 3.75 & 4.45 & 4.45 \\
\hline 2000 Q3 & 6.00 & .. & .. & .. & .. & 6.12 & 5.63 & 5.17 & 4.50 & 4.88 \\
\hline Q4 & 6.00 & .. & .. & .. & .. & 5.99 & 5.32 & 4.96 & 4.44 & 4.73 \\
\hline 2001 Q1 & 5.86 & .. & .. & .. & .. & 5.64 & 4.99 & 4.76 & 4.40 & 4.66 \\
\hline Q2 & 5.36 & .. & .. & .. & .. & 5.23 & 5.12 & 5.02 & 4.87 & 5.10 \\
\hline Q3 & 5.05 & .. & .. & .. & .. & 4.93 & 5.07 & 4.96 & 4.82 & 5.04 \\
\hline 2002 Q1 & 4.00 & .. & .. & .. & .. & 4.01 & 5.02 & 4.97 & 4.80 & 5.03 \\
\hline Q2 & 4.00 & .. & .. & .. & .. & 4.10 & 5.16 & 5.16 & 5.02 & 5.23 \\
\hline Q3 & 4.00 & .. & .. & .. & .. & 3.95 & 4.58 & 4.70 & 4.60 & 4.77 \\
\hline Q4 & 4.00 & .. & .. & .. & .. & 3.92 & 4.36 & 4.59 & 4.58 & 4.67 \\
\hline 2003 Q1 & 3.85 & .. & .. & .. & .. & 3.73 & 4.00 & 4.34 & 4.47 & 4.50 \\
\hline Q2 & 3.75 &.. &.. &.. & .. & 3.57 & 3.89 & 4.28 & 4.54 & 4.51 \\
\hline Q3 & 3.53 & .. & .. & .. & .. & 3.50 & 4.26 & 4.57 & 4.72 & 4.72 \\
\hline Q4 & 3.65 & .. & .. & .. & .. & 3.86 & 4.78 & 4.92 & 4.82 & 4.86 \\
\hline 2004 Q1 & 3.91 & .. & .. & .. & .. & 4.11 & 4.60 & 4.73 & 4.68 & 4.68 \\
\hline Q2 & 4.22 & .. & .. & .. & .. & 4.51 & 4.99 & 5.04 & 4.87 & 4.87 \\
\hline Q3 & 4.65 & .. & .. & .. & .. & 4.85 & 4.95 & 4.95 & 4.72 & 4.73 \\
\hline Q4 & 4.75 & .. & .. & .. & .. & 4.82 & 4.56 & 4.62 & 4.50 & 4.52 \\
\hline 2005 Q1 & 4.75 & .. & .. & .. & .. & 4.85 & 4.57 & 4.60 & 4.51 & 4.56 \\
\hline Q2 & 4.75 & .. & .. & .. & .. & 4.83 & 4.34 & 4.40 & 4.39 & 4.44 \\
\hline Q3 & 4.59 & .. & .. & .. & .. & 4.55 & 4.17 & 4.24 & 4.27 & 4.32 \\
\hline Q2 & 4.50 &.. &.. &.. & .. & 4.64 & 4.62 & 4.55 & 4.31 & 4.31 \\
\hline Q3 & 4.66 & .. & .. & .. & .. & 4.85 & 4.70 & 4.55 & 4.27 & 4.26 \\
\hline Q4 & 4.89 & .. & .. & .. & .. & 5.17 & 4.76 & 4.50 & 4.16 & 4.15 \\
\hline 2007 Q1 & 5.22 & .. & .. & .. & .. & 5.49 & 5.05 & 4.76 & 4.36 & 4.37 \\
\hline Q2 & 5.40 & .. & .. & .. & .. & 5.72 & 5.38 & 5.10 & 4.69 & 4.69 \\
\hline Q3 & 5.74 & .. & .. & .. & .. & 6.29 & 5.28 & 5.09 & 4.67 & 4.63 \\
\hline Q4 & 5.69 & .. & .. & .. & .. & 6.30 & 4.73 & 4.74 & 4.54 & 4.50 \\
\hline 2008 Q1 & 5.35 & .. & .. & .. & .. & 5.68 & 4.24 & 4.51 & 4.50 & 4.45 \\
\hline Q2 & 5.03 & .. & .. & .. & .. & 5.86 & 4.69 & 4.87 & 4.79 & 4.64 \\
\hline Q3 & 5.00 & .. & .. & .. & .. & 5.81 & 4.63 & 4.75 & 4.72 & 4.58 \\
\hline Q4 & 3.37 & .. &.. &.. & .. & 4.65 & 3.57 & 4.22 & 4.63 & 4.34 \\
\hline 2009 Q1 & 1.07 & .. & .. & .. & .. & 2.06 & 2.62 & 3.63 & 4.42 & 4.28 \\
\hline Q2 & 0.50 & .. & .. & .. & .. & 1.33 & 2.74 & 3.68 & 4.62 & 4.59 \\
\hline Q3 & 0.50 & .. & .. & .. & .. & 0.82 & 2.91 & 3.83 & 4.42 & 4.45 \\
\hline Q4 & 0.50 & .. & .. & .. & .. & 0.59 & 2.75 & 3.85 & 4.35 & 4.49 \\
\hline
\end{tabular}

1 The monthly rates are now shown in Table 7.1J Part 2.

2 Ceased to be compiled as from Q2 1999.

3 The model used to derive these estimates is a spline-based technique,

known as the "Variable Roughness Penalty" (VRP) model which replaces

the formerly used Svensson method. For further information see "Supple-

mentary Information". 


\subsection{A Consumer Price index, Retail Prices Index and other selected indices}

\begin{tabular}{|c|c|c|c|c|c|c|c|c|}
\hline & \multicolumn{2}{|c|}{$\begin{array}{c}\text { Consumer prices index } \\
(\mathrm{CPI})^{1,2}\end{array}$} & \multicolumn{2}{|c|}{$\begin{array}{c}\text { All items } \\
\text { retail prices index (RPI) }\end{array}$} & \multicolumn{4}{|c|}{ All items RPI excluding } \\
\hline & \multirow[b]{2}{*}{$\begin{array}{r}\text { Index } \\
(2005=100)\end{array}$} & \multirow[b]{2}{*}{$\begin{array}{r}\text { Percentage } \\
\text { change } \\
\text { over } \\
12 \text { months }\end{array}$} & \multirow[b]{2}{*}{$\begin{array}{r}\text { Index } \\
(\text { Jan 13, } \\
1987=100)\end{array}$} & \multirow[b]{2}{*}{$\begin{array}{r}\text { Percentage } \\
\text { change } \\
\text { over } \\
12 \text { months }\end{array}$} & \multicolumn{2}{|c|}{$\begin{array}{l}\text { mortgage interest } \\
\text { payments (RPIX) }\end{array}$} & \multicolumn{2}{|c|}{$\begin{array}{l}\text { mortgage interest payments } \\
\text { and indirect taxes (RPIY) }\end{array}$} \\
\hline & & & & & $\begin{array}{r}\text { Index } \\
(\text { Jan 13, } \\
1987=100)\end{array}$ & $\begin{array}{r}\text { Percentage } \\
\text { change } \\
\text { over } \\
12 \text { months }\end{array}$ & $\begin{array}{r}\text { Index } \\
(\operatorname{Jan} 13 \\
1987=100)\end{array}$ & $\begin{array}{r}\text { Percentage } \\
\text { change } \\
\text { over } \\
12 \text { months }\end{array}$ \\
\hline & D7BT & D7G7 & CHAW & $\mathrm{CZBH}$ & $\mathrm{CHMK}$ & $\mathrm{CDKQ}$ & CBZW & CBZX \\
\hline 2005 & 100.0 & 2.1 & 192.0 & 2.8 & 188.2 & 2.3 & 179.4 & 2.2 \\
\hline 2006 & 102.3 & 2.3 & 198.1 & 3.2 & 193.7 & 2.9 & 184.8 & 3.0 \\
\hline 2007 & 104.7 & 2.3 & 206.6 & 4.3 & 199.9 & 3.2 & 190.8 & 3.2 \\
\hline 2008 & 108.5 & 3.6 & 214.8 & 4.0 & 208.5 & 4.3 & 199.2 & 4.4 \\
\hline 2009 & 110.8 & 2.2 & 213.7 & -0.5 & 212.6 & 2.0 & 204.8 & 2.8 \\
\hline 2006 Q2 & 102.1 & 2.3 & 197.6 & 3.0 & 193.4 & 2.8 & 184.3 & 2.8 \\
\hline Q3 & 102.8 & 2.4 & 199.3 & 3.5 & 194.8 & 3.2 & 185.9 & 3.3 \\
\hline Q4 & 103.6 & 2.7 & 201.4 & 4.0 & 196.4 & 3.5 & 187.6 & 3.6 \\
\hline 2007 Q1 & 103.7 & 2.9 & 203.0 & 4.5 & 197.2 & 3.7 & 188.4 & 3.9 \\
\hline & 104.8 & 2.6 & 206.3 & 4.4 & 200.0 & 3.4 & 190.7 & 3.5 \\
\hline Q3 & 104.6 & 1.8 & 207.1 & 3.9 & 200.1 & 2.7 & 190.9 & 2.7 \\
\hline Q4 & 105.7 & 2.1 & 209.8 & 4.2 & 202.5 & 3.1 & 193.3 & 3.0 \\
\hline 2008 Q1 & 106.2 & 2.4 & 211.1 & 4.0 & 204.1 & 3.5 & 195.0 & 3.5 \\
\hline Q2 & 108.3 & $\begin{array}{l}3.4 \\
3.4\end{array}$ & 215.3 & 4.4 & 208.8 & 4.4 & 199.1 & 4.4 \\
\hline Q3 & 109.7 & 4.8 & 217.4 & 5.0 & 210.8 & 5.3 & 201.3 & 5.4 \\
\hline Q4 & 109.8 & 3.9 & 215.5 & 2.7 & 210.2 & 3.8 & 201.5 & 4.2 \\
\hline 2009 Q1 & 109.4 & 3.0 & 210.9 & -0.1 & 209.0 & 2.4 & 201.5 & 3.3 \\
\hline Q2 & 110.6 & 2.1 & 212.6 & -1.3 & 211.8 & 1.4 & 203.9 & 2.4 \\
\hline Q3 & 111.3 & 1.5 & 214.4 & -1.4 & 213.6 & 1.3 & 205.7 & 2.2 \\
\hline Q4 & 112.1 & 2.1 & 216.9 & 0.6 & 216.0 & 2.8 & 208.2 & 3.3 \\
\hline 2007 Jan & 103.2 & 2.7 & 201.6 & 4.2 & 196.1 & 3.5 & 187.3 & 3.7 \\
\hline Feb & 103.7 & 2.8 & 203.1 & 4.6 & 197.1 & 3.7 & 188.4 & 3.9 \\
\hline Mar & 104.2 & 3.1 & 204.4 & 4.8 & 198.3 & 3.9 & 189.5 & 4.0 \\
\hline Apr & 104.5 & 2.8 & 205.4 & 4.5 & 199.3 & 3.6 & 190.0 & 3.7 \\
\hline May & 104.8 & 2.5 & 206.2 & 4.3 & 200.0 & 3.3 & 190.7 & 3.4 \\
\hline Jun & 105.0 & 2.4 & 207.3 & 4.4 & 200.7 & 3.3 & 191.4 & 3.3 \\
\hline Jul & 104.4 & 1.9 & 206.1 & 3.8 & 199.4 & 2.7 & 190.1 & 2.6 \\
\hline Aug & 104.7 & 1.8 & 207.3 & 4.1 & 200.1 & 2.7 & 190.9 & 2.6 \\
\hline Sep & 104.8 & 1.8 & 208.0 & 3.9 & 200.8 & 2.8 & 191.6 & 2.8 \\
\hline Oct & 105.3 & 2.1 & 208.9 & 4.2 & 201.6 & 3.1 & 192.3 & 3.0 \\
\hline Nov & 105.6 & 2.1 & 209.7 & 4.3 & 202.4 & 3.2 & 193.2 & 3.0 \\
\hline Dec & 106.2 & 2.1 & 210.9 & 4.0 & 203.5 & 3.1 & 194.4 & 3.1 \\
\hline 2008 Jan & 105.5 & 2.2 & 209.8 & 4.1 & 202.7 & 3.4 & 193.5 & 3.3 \\
\hline Feb & 106.3 & 2.5 & 211.4 & 4.1 & 204.3 & 3.7 & 195.2 & 3.6 \\
\hline Mar & 106.7 & 2.5 & 212.1 & 3.8 & 205.3 & 3.5 & 196.3 & 3.6 \\
\hline Apr & 107.6 & 3.0 & 214.0 & 4.2 & 207.2 & 4.0 & 197.5 & 3.9 \\
\hline May & 108.3 & 3.3 & 215.1 & 4.3 & 208.7 & 4.4 & 199.0 & 4.4 \\
\hline Jun & 109.0 & 3.8 & 216.8 & 4.6 & 210.4 & 4.8 & 200.8 & 4.9 \\
\hline Jul & 109.0 & 4.4 & 216.5 & 5.0 & 210.0 & 5.3 & 200.4 & 5.4 \\
\hline Aug & 109.7 & 4.7 & 217.2 & 4.8 & 210.6 & 5.2 & 201.2 & 5.4 \\
\hline Sep & 110.3 & 5.2 & 218.4 & 5.0 & 211.8 & 5.5 & 202.4 & 5.6 \\
\hline Oct & 110.0 & 4.5 & 217.7 & 4.2 & 211.1 & 4.7 & 201.7 & 4.9 \\
\hline Nov & 109.9 & 4.1 & 216.0 & 3.0 & 210.2 & 3.9 & 200.8 & 3.9 \\
\hline Dec & 109.5 & 3.1 & 212.9 & 0.9 & 209.2 & 2.8 & 201.9 & 3.9 \\
\hline 2009 Jan & 108.7 & 3.0 & 210.1 & 0.1 & 207.5 & 2.4 & 200.0 & 3.4 \\
\hline Feb & 109.6 & 3.2 & 211.4 & - & 209.5 & 2.5 & 202.1 & 3.5 \\
\hline Mar & 109.8 & 2.9 & 211.3 & -0.4 & 209.9 & 2.2 & 202.5 & 3.2 \\
\hline Apr & 110.1 & 2.3 & 211.5 & -1.2 & 210.7 & 1.7 & 202.9 & 2.7 \\
\hline May & 110.7 & 2.2 & 212.8 & -1.1 & 212.0 & 1.6 & 204.1 & 2.6 \\
\hline Jun & 111.0 & $\begin{array}{l}1.8 \\
\text { lo }\end{array}$ & 213.4 & -1.6 & 212.6 & 1.0 & 204.7 & 1.9 \\
\hline Jul & 110.9 & 1.8 & 213.4 & -1.4 & 212.6 & 1.2 & 204.7 & 2.1 \\
\hline Aug & 111.4 & 1.6 & 214.4 & -1.3 & 213.6 & 1.4 & 205.8 & 2.3 \\
\hline Sep & 111.5 & 1.1 & 215.3 & -1.4 & 214.5 & 1.3 & 206.5 & 2.0 \\
\hline Oct & 111.7 & 1.5 & 216.0 & -0.8 & 215.1 & 1.9 & 207.3 & 2.8 \\
\hline Nov & 112.0 & 1.9 & 216.6 & 0.3 & 215.8 & 2.7 & 207.9 & 3.5 \\
\hline Dec & 112.6 & 2.9 & 218.0 & 2.4 & 217.2 & 3.8 & 209.5 & 3.8 \\
\hline
\end{tabular}

1 Prior to 10 December 2003, the consumer prices index (CPI) was published 3 The taxes excluded are council tax, VAT, duties, vehicle excise duty, insurance in the UK as the harmonised index of consumer prices (HICP). 